\title{
Study Behavior in Computing Education-A Systematic Literature Review
}

\author{
MADELEINE LORÅS, GUTTORM SINDRE, HALLVARD TRATTEBERG, and \\ TROND AALBERG, Norwegian University of Science and Technology, Norway
}

\begin{abstract}
As the field of computing education grows and matures, it has become essential to unite computing education and higher education research. Educational research has highlighted that how students study is crucial to their learning progress, and study behaviors have been found to play an important role in students' academic success. This article presents the main results of a systematic literature review intended to determine what we know about the study behaviors of computing students and the role of educational design in shaping them. A taxonomy of study behaviors was developed and used to clarify and classify the definitions of study behavior, process, strategies, habits, and tactics as well as to identify their relationship to the educational context. The literature search resulted in 107 included papers, which were analyzed according to defined criteria and variables. The review of study behavior terminology found that the same terms are used to describe substantially different study behaviors, and the lack of standard terminology makes it difficult to compare findings from different papers. Furthermore, it was more common for papers to use study behaviors to explain other aspects of students rather than exploring and understanding them. Additionally, the results revealed a tendency to focus on specific educational contexts, predominantly introductory programming courses. Although computing education as a field is well equipped to expand the knowledge about both study behaviors and their connection to the educational context, the lack of common terminology and theories limits the impact. The taxonomy of study behaviors in computing education proposed in this article can contribute to contextualizing the research in such a way that researchers and educators across institutional borders can compare and utilize results. Last, the article outlines some areas for future research and recommendations for practice.
\end{abstract}

CCS Concepts: - Social and professional topics $\rightarrow$ Computing education; Computer science education;

Additional Key Words and Phrases: Computing education, study behavior, study process, study strategies, study habits, study tactics, educational context

\section{ACM Reference format:}

Madeleine Lorås, Guttorm Sindre, Hallvard Trætteberg, and Trond Aalberg. 2021. Study Behavior in Computing Education-A Systematic Literature Review. ACM Trans. Comput. Educ. 22, 1, Article 9 (October 2021), 40 pages.

https://doi.org/10.1145/3469129

The work in this article was conducted at Excited Centre for Excellence, publicly funded through DIKU.

Authors' address: M. Låras, G. Sindre, H. Tratteberg, and T. Aalberg, Norwegian University of Science and Technology, Trondheim, Norway; emails: madeleine.loras@ntnu.no, guttorm.sindre@ntnu.no, hal@ntnu.no, trond.aalberg@ntnu.no. Permission to make digital or hard copies of part or all of this work for personal or classroom use is granted without fee provided that copies are not made or distributed for profit or commercial advantage and that copies bear this notice and the full citation on the first page. Copyrights for third-party components of this work must be honored. For all other uses, contact the owner/author(s).

(C) 2021 Copyright held by the owner/author(s).

1946-6226/2021/10-ART9 \$15.00

https://doi.org/10.1145/3469129 


\section{INTRODUCTION}

Study behaviors have been found to be crucial to students' academic success [30]. Within computing education, we know that students exhibit many different behaviors when studying and learning computing concepts $[12,109,164]$ and that differences between effective and ineffective students can often be explained by such behaviors [134]. Research on study behaviors in computing education has seen an increase in focus over recent years [100]. Specifically, researchers have focused on gathering and analyzing behavior data to identify difficulties, design interventions, encourage change, and predict success and performance. However, this previous work on computing students study behavior is fragmented. For example, many different terms are used to describe the same behaviors $[130,152]$. There is also still a need for further research focused both on the behaviors and definitions in use and on the role of the educational context in computing education. Therefore, this article explores how the computing education research community has approached computing students study behavior. ${ }^{1}$ More specifically, the research questions are as follows:

- RQ1: How are study behaviors defined in computing education research?

- RQ2: In what ways are study behaviors included in computing education research?

- RQ3: What is known about the role of educational context in shaping study behaviors in computing education?

To answer these questions, we performed an extensive systematic literature review of study behavior in computing education. To do so, we developed a taxonomy of study behaviors by combining research in higher education, psychology, and learning sciences. This work takes a broad perspective on study behaviors, including everything from cognitive levels of engagement to concrete tools students use, making the contribution of this article different than other reviews. Previous reviews within computing education have looked at specific aspects of students' behaviors, such as metacognition [130] or the role of behaviors in predicting performance [71]. This review reveals that the variety of terminology and infrequent use of theoretical definitions limit the value of the research when it comes to generalizing and transferring knowledge between educational contexts. Based on the results of this literature review, the taxonomy was updated to include the study behavior terms identified in computing education trough the analysis. This extended taxonomy provides a tool for classifying the behaviors present in computing education literature, and other researchers and educators can use it as a tool in the future.

The rest of this article is organized as follows: In Section 2, we present the taxonomy and definitions on which the analysis is based. Section 3 presents the methodology used for the literature review by describing how papers were selected and analyzed. In Sections 4, 5, and 6, we present the findings to the three research questions, respectively. Section 7 provides a discussion of these findings and their implications and outlines opportunities for future research. Finally, Section 8 summarizes and concludes the article.

\section{THEORETICAL PERSPECTIVES ON STUDY BEHAVIOR}

Study behavior has, over the years, been the focus of many research papers, although the terms and definitions described are often inconsistent [100, 152]. Tressel, Lajoie, and Duffys review from 2019 addresses this fragmented domain and proposes a hierarchical terminology based on research from recent decades [152]. They define study behavior as "any actions students make when preparing for, or taking part in, study-based activities" [152, p. 121]. This definition is intentionally broad

\footnotetext{
${ }^{1}$ To limit the confusion between the terms study behavior and research study, any references to study or studies in this article refers to aspects of study behaviors. Any references to research studies will use different terminology.
} 


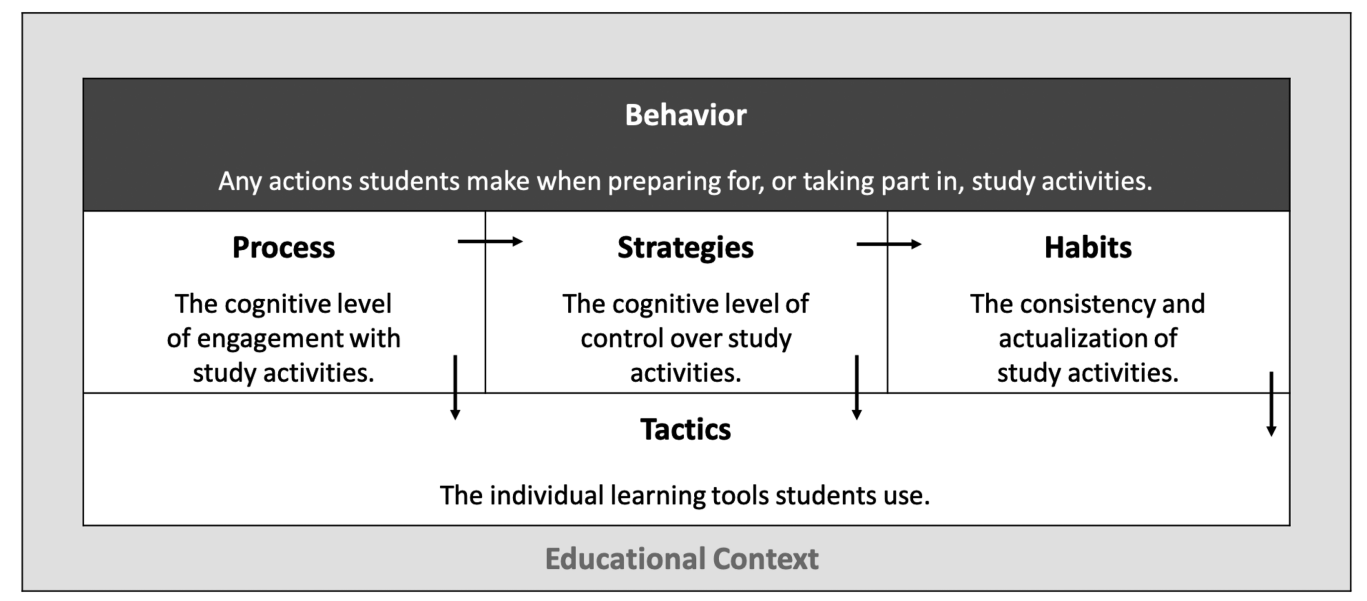

Fig. 1. Study behavior taxonomy: Definition and hierarchy of study behaviors.

and encapsulates all study terms. Based on this hierarchy, Figure 1 offers an outline of a taxonomy of study behaviors, which is the foundation of the analysis in this article.

A taxonomy is a system for naming and organizing things into groups that share similar qualities [35]. Self-regulation and metacognition, for example, share similar qualities and are therefore placed under study strategies [130]. Furthermore, the taxonomy as a tool serves two main purposes: It classifies the different constructs of study behavior and illustrates how they are related. The taxonomy above is based on the idea that any study term (i.e., self-regulation, time engagement, approach to learning) is placed in only one behavior construct (i.e., process, strategies, habits). Last, because the educational context construct is related to all behaviors, it is represented as such by being the background in Figure 1. Process and strategies primarily relate to the cognitive level. Habits and tactics primarily relate to the concrete what students do and use. These boundaries are not definite, and there are cognitive and concrete elements to all four constructs. Together, these four behavior constructs compose a more general construct of behavior, and study terms can be placed within such a construct. In addition to Tressel et al. [152], we draw from other research and theories within general education and computing education to further define the different terms.

The taxonomy as depicted in Figure 1 should be read from top left to bottom, with each row representing one level. The upper levels are grounded in the lower levels, and the behaviors on the same level inform each other, as illustrated by arrows. Thus, study process, strategies, and habits are closely connected and affect each other, and they act as drivers of the choice and use of tactics. For example, the case of a student working on a programming assignment illustrates how the levels of the taxonomy interact: First, the students level of engagement sets the foundation for this work. If the student takes a calculated approach, then the strategies she chooses will be guided by time management and self-regulation abilities with the goal of meeting a deadline, not necessarily understanding the concept. Furthermore, the habits in this case may be aimed toward limiting the total time engagement and perhaps not going to all lectures. Last, the tactics the student employs are guided by all these constructs, aiming for the deadline with strategic decisions, such as engaging in trial and error, high compilation frequency, and using the internet to quickly debug problems. In this hypothetical scenario, the student also navigates through the educational context, for example, attending organized teaching activities if needed, leaning on the social environment or utilizing labs or other study spaces. It is important to note here that this taxonomy does not state how a student studies, neither does it model ideal behaviors. This hypothetical is 
merely an example of how the constructs in the taxonomy work together. In the following subsections, we define terms and explore theories related to the behavior constructs process, strategies, habits, and tactics as well as the educational context.

\subsection{Process}

Study process in this article is defined as cognitive engagement with study activities, that is, students' internal approaches to studying and learning. It has been established that information processing consists of different levels of depth in cognitive processing [29]. There are two main directions within the many theoretical frameworks necessary to understand the study process described in behavior literature: student approaches to learning and learning styles.

The student approaches to learning (SAL) framework is a theory developed by Marton and in Säljö 1976 [106] and further developed by Biggs [14] and Entwistle and Ramsden [43]. According to SAL theory, students learning and studying process can be categorized into two categories: deep cognitive processing and surface cognitive processing. The deep approach is an internally driven motivation and commitment to learning, where the intention to extract meaning produces active learning. In contrast, the surface approach is externally driven and concerns coping with various tasks; it is considered a much more restricted learning process. More recently, Biggs described this difference as follows: The surface approach refers to activities of an inappropriately low cognitive level, which yields fragmented outcomes that do not convey the meaning of the encounter, and the deep approach refers to activities that are appropriate to handling the task so an appropriate outcome is achieved [15, p. 42]. Biggs and colleagues developed a questionnaire to measure whether students use a deep and surface approach [16], and it is commonly used to evaluate teaching initiatives and student learning approaches. The revised two-factor Study Process Questionnaire has been adapted and validated across countries and cultures (e.g., Reference [53])

In addition to SAL theory, the notion of learning styles came from experiential learning theory and was first introduced by Kolb in the 1980s [87]. Experiential learning refers to the generalized differences in learning orientation based on the degree to which people emphasize the four modes of learning process [88, p. 76]. Many different frameworks for learning styles have been developed since then, but a common theme is describing learner characteristics in different dimensions [26]. On the topic of learning styles, it is important to address a substantial critique voiced over the years: the lack of empirical justification when matching instructional methods to the supposed learning styles of individual students [116]. Several reviews have found that there is inadequate evidence to justify incorporating learning style assessments into educational practices (see, for example, Pashler et al. [123] and Coffield [26]). Furthermore, learning styles have been criticized for the potentially harmful practice of diagnosing students [115] as well as for the commercial profits being made from the sale of tools and software [26]. Even though learning styles still seem to be in use in the educational system, many researchers view the framework as debunked [115].

In this review, we make a distinction between learning styles and the SAL framework; however, the latter has also received some skepticism $[64,133]$. Whereas learning styles are criticized for the lack of empirical evidence, SAL theory has been miscited and misunderstood in many research papers [133]. Moreover, the perspective of SAL as a model, rather than a theory, has caused deep and surface approaches to learning to result in deep and surface learners [104,133]. Defenders of SAL theory acknowledge limitations to how SAL should be used and emphasize room for further development and contextualization of the theory $[26,104]$. Indeed, SAL theory does not aim to characterize a learner and is dependent on the context [104]. A student may adopt a deep approach in one context and a surface approach in another, depending on the characteristics of the context and the learners interpretation thereof [44]. We therefore argue that there is reason to distinguish between learning styles and student approaches to learning (keeping in mind that learning styles 
are criticized in the literature and that SAL theory should be viewed with an appropriate level of academic skepticism).

\subsection{Strategies}

Besides process, it is also important to understand strategies relating to studying. Study strategies are in this article defined as one's level of cognitive control over study activities. In this definition, we have combined some theoretical perspectives to clarify the terminology. First, this definition includes what Tressel et al. [152] define as skills and strategies because that definition is more in line with other definitions, such as Credé and Kuncel [30] and Prather et al. [130]. Second, differentiating between a skill and a strategy in practice was challenging and unnecessarily confusing. For example, the term self-regulation, which is the process of executing cognitive control during a task [131], could be considered both a skill and a strategy. To avoid the same terms being categorized into two behavior constructs, we combined the concepts of skills and strategies and used the term strategies to refer to both because the word skills has a very solid establishment within competency frameworks [52].

Within this definition of strategies fall the study terms metacognition and self-regulation, time management, motivation, and affective constructs. First, it is important to define and differentiate metacognition and self-regulation. Prather et al. [130] did a systematic review of metacognition and self-regulation in programming education in 2020, clarifying terms and measurements. They define metacognition as knowledge about one's own cognitive control, whereas self-regulation is the process of executing cognitive control [130, p. 3]. In other words, the difference lies in knowledge versus execution. It has also been pointed out that the environment plays an important role in self-regulation, whereas metacognition is focused on the mind of the individual [37]. Together, they constitute cognitive control, and they are closely connected [82]. Within cognitive control, time management is important and is an indicative measurement of self-regulation [165].

Last, there are the affective constructs [92], also referred to as non-cognitive factors [136]. Affective constructs are terms related to emotions, attitudes, feelings, and beliefs [152]. Examples of affective constructs common in the literature on study behaviors are epistemological beliefs [72], personality [129], confidence, attitudes [68], self-efficacy, and grit [38].

\subsection{Habits}

In addition to strategies, habits also play an important role in how study behaviors affect the success of computing students. Study habits is one of the most loosely defined terms in the literature $[30,152]$. Tressel et al. [152] argue that study habits should be defined by the consistency of study behaviors, regularity in the use of study strategies, and the study environment. This definition means that study habits are informed by the study process and strategies but are related to explicit behaviors. In this article, study habits are defined as the consistency and actualization of study activities, which means that the interaction with the environment has been removed (see Section 2.5 for more).

An important aspect of study habits in our definition is that it is related to the activities students partake in when studying. Whereas process and strategies are related to purely cognitive processes, habits, and tactics are concrete. In a way, process and strategies can be seen as aspects of why and habits and tactics as what. Nevertheless, research on study habits commonly includes the ability to manage time [174]. We propose to differentiate time management and time engagement based on this distinction between why and what. In Credé and Kuncel [30]'s definition of study habits, they are related to the frequency of study sessions or time engagement, whereas time management is related to the planning and intention of time spent studying [165]. Therefore, time engagement is 
a study term within the construct of habits, and time management is a term within the construct of strategies.

\subsection{Tactics}

Last, tactics are defined as the individual learning tools a student uses during their studying [152, p. 120]. Examples of study tactics are note-taking, self-testing and viewing videos. Within computing education, there are many specific tactics, such as debugging and use of integrated development environment tools (IDEs) [154]. The use of tactics is informed by the study process, strategies, and habits. Research on tactics has revealed that students success is related to the awareness of using certain tactics and the breadth of tactics used [57]. Like habits, tactics are aspects of what students actually do; however, the choice and use of specific tactics are connected to cognitive levels of engagement and control. When differentiating between habits and tactics, one can consider their origin and consistency. Habits are consistent routines that students have acquired, while tactics are concrete elements informed by the habits as well as by process and strategy. Furthermore, tactics are often discipline-specific and include tools unique for computing, such as debugging and pair programming.

\subsection{The Educational Context}

Students study behaviors happen in close relation to the educational context, here defined as the organized teaching and learning activities, learning environment, and curriculum [17]. Tressel et al. [152] consider students' interaction with the learning environment to be part of a student's study habits; however, we find it more logical to view the educational context as a factor affecting all study behaviors. The educational context involves physical, cultural, and social aspects and is inherently linked to cognitive and concrete aspects of study behaviors [9, 36]. Bandura's theory of reciprocal determinism states that a person's behavior influences and is influenced by personal factors and the social environment [9]. Teaching activities are the organized events involving an educator, such as lectures, seminars, and assessments. Learning activities reference the organized activities students are expected to do independently, such as assignments, projects, quizzes, and general studying. The learning environment includes diverse physical locations, social contexts, and cultures in which students learn, including their interactions with teaching and learning activities and content and curriculum. How a student studies is influenced not just by the educational context but also by the student's perceptions of the learning environment [97]. Thus, a student's ability to navigate within the educational context is a central aspect of study behavior, linked to process [17], strategies [37], and habits [152].

In this section, we outlined the theoretical perspectives and definitions underpinning this literature review. The taxonomy in Figure 1 outlines the constructs and terms within research on study behavior from general educational domains. After presenting the methodology in Section 3, we will present the results of how study behaviors are defined and used within the computing education context.

\section{METHODOLOGY}

A systematic literature review (SLR) must follow well-defined protocols, guidelines, and academic norms. The current research is positioned at the intersection between higher education research and computing education. Within the computing and computing education fields, it is common to follow Kitchenham's procedures for performing systematic reviews, made to "introduce the concept of rigorous reviews of current empirical evidence to the software engineering community" [86, p. 1]. Within higher education research, there are several similar procedural guidelines. Bearman et al. [10] reviewed the use of systematic literature reviews in the field and outlined 
several common types. The current SLR is based on the Kitchenham procedure, which largely overlaps with what Bearman et al. refer to as the "Campbell-Cochrane systematic review." Common for both is the transparent and systematic nature of the search procedure, data extraction, and assessment, which is described for the current SLR in this section [10,86].

\subsection{Systematic Review Planning}

To the authors' knowledge, no previous work has produced a systematic and comprehensive review of the existing published work on study behaviors in computing education. Thus, this article systematizes and summarizes the empirical work in the field and provides researchers and educators with insights for moving forward.

3.1.1 Search Strings. As described above, the various uses of terminology in the domain of study behaviors make it difficult to synthesize and compare results of various studies. In addition, the identification of relevant literature also becomes difficult in this regard. For this systematic review, we kept the definition of study behavior as broad as possible to identify these discrepancies and to resolve them. Therefore, the search terms used for study behavior include all terms in the hierarchy of Tressel et al. [152], namely, study behavior, process, skills, habits, strategies, and tactics.

To limit the search to computing education, we again ran into a definition problem, since computing education is denoted by a variety of terms throughout the world. In response to this problem, we chose to include the terms used in the 2005 Joint Task Force Computing Curricula [50], including the following: computer science, computer engineering, information systems, information technology, software engineering, and computing. Last, we limited the search to include education, specifically higher education. By using the search terms AND and OR, we created the following search string (in italics):

- Study behavior: "(("study behavior" OR "study process" OR "study skills" OR "study habits" OR "study strategies" OR "study tactics" OR learning behavior OR studying)

- Computing: AND ("computer science” OR engineering OR programming OR cs OR CS OR computing OR ICT)

- Education: AND (education OR "higher education"))"

The search terms were prototyped in a trial search [86, 100], confirming that the search string was reliable. We also learned that inclusion decisions based only on abstracts were not going to be possible, so the review process was adjusted to include full-text reviews.

3.1.2 Search Strategy and Selection Criteria. To find papers relevant for the review, we decided to include peer-reviewed empirical papers written in English that addressed study behaviors within higher computing education. Initially, the authors considered four inclusion criteria and four exclusion criteria to select papers for further analysis, as shown in Table 1. Next, we continued the selection process according to the set of seven quality criteria shown in Table 2 . These quality criteria were informed by the Critical Appraisal Skills Programme [39, 83], which specifies the rigor, credibility, and relevance that need to be considered when evaluating the quality of papers.

The search for literature was done in several databases, using the "search within anything" function. First, we searched in the IEEE and ACM digital libraries, because they cover many of the most relevant conferences and journals in computing education research. In addition, we searched the more general libraries of Scopus, Web of Science, and Engineering Village to cover more literature. Table 3 shows that the initial search from these databases yielded 1,701 results, including duplicates. Searches in the Springer, ERIC, Elsevier, and SAGE databases were also performed; however, the results from these were either too large $(n>10,000)$ or too broad (top listed papers were on 
Table 1. Inclusion/Exclusion Criteria

\section{Inclusion criteria}

The research was done within computing education or with a majority of computing students.

The research was done in higher education.

The research includes aspects of study behavior.

The research is empirical.

\section{Exclusion criteria}

The paper is not a research study or peer-reviewed paper (e.g., extended abstracts, posters, reviews, blogs).

The paper is not written in English.

The paper is not accessible via university subscriptions.

The paper is under four pages.

Table 2. Quality Criteria

1. Does the paper address the research problem?

2. Is there a clear statement of the aims of the research?

3. Was the research design appropriate to determine the aims of the research?

4. Does the paper clearly determine the research methods (subjects, instruments, data collection, data analysis)?

5. Was the data analysis sufficiently rigorous?

6. Is there a clear statement of findings?

7. Is the paper of value for research or practice?

Table 3. Search Results by Source

\begin{tabular}{lc}
\hline Database & Initial extraction \\
\hline ACM Digital Library & 644 \\
Engineering Village & 589 \\
IEEE Xplore & 107 \\
Scopus & 217 \\
Web of Science & 145 \\
\hline Total & 1,701 \\
\hline
\end{tabular}

irrelevant topics). Upon inspection, there seemed to be a significant overlap in relevant papers between these databases and the ones included in this review (ACM, IEEE, EV, Scopus, and WoS).

\subsection{Systematic Review Execution}

The whole process of searching for, including, and excluding papers is illustrated in Figure 2. The first step was gathering papers from the various databases, as listed in Table 3. The next step involved removing duplicates and non-relevant item types, such as posters, books, and patents. With the remaining 1,301 papers, a read-through of titles and publication names was done to remove obviously irrelevant papers (step 3). In this phase, papers in unrelated fields, such as medicine and agriculture, were removed as well as blogs and posters that had, for some reason, survived step 2. Because of the broad search terms, a substantial number of titles were removed in this phase, resulting in 904 papers for abstract review. Next, a read-through of abstracts-and full text if needed-was done using the inclusion criteria presented in Table 1 (step 4). We evaluated papers in the following way: 


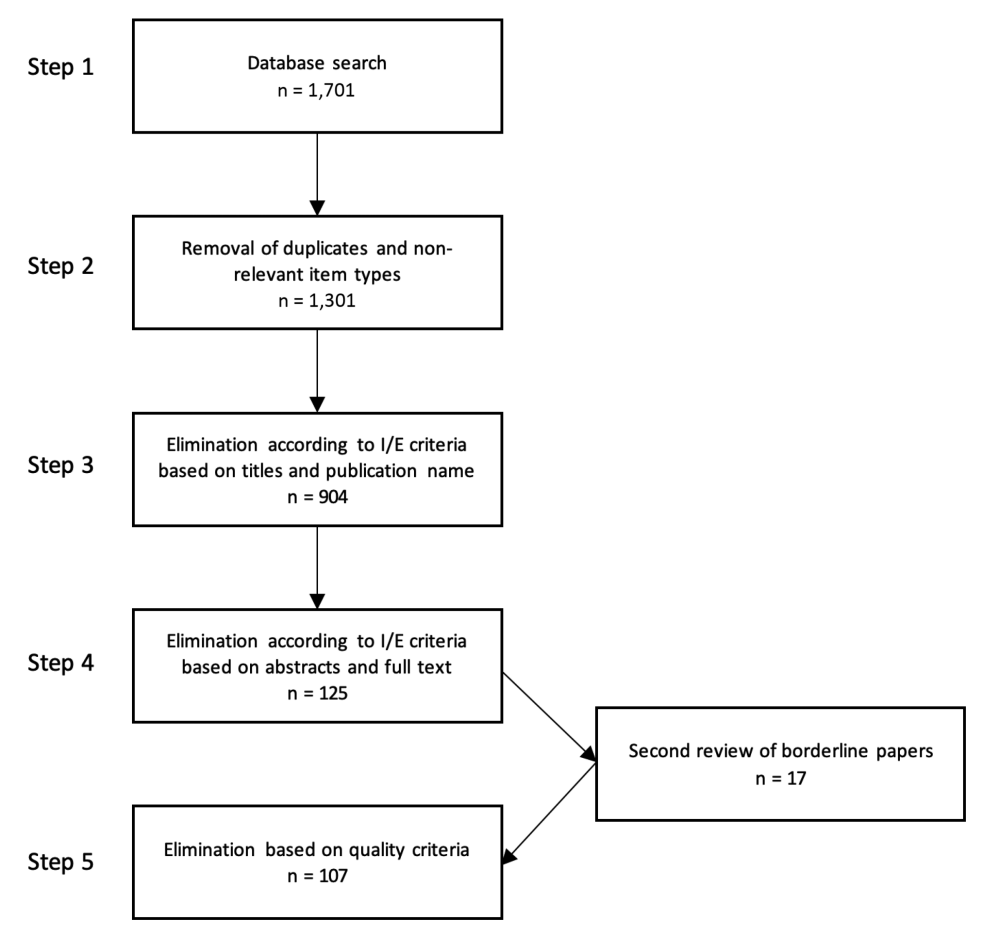

Fig. 2. Overview of search and selection process.

- Does the abstract reveal that the paper should be excluded? For example, this step excluded papers relating to the K-13 level, a different field (mathematics, physics), and papers not focused on behavior.

- If the abstract was inconclusive, then the full text was investigated. For example, the paper was excluded if it was about behavior but made no reference to context, field, or level of education.

- If the abstract was conclusive, then a full-text check was still performed to ensure the page number and language. For example, some papers were about study behavior in computing education at the university level; however, it was initially not clear what type of publication it was.

During abstract review, 723 papers were excluded, 125 were included, and 56 were labeled as borderline. A second review was performed on the borderline papers, which resulted in 17 new inclusions. Until this point, the first author had performed the search and selection process alone, but for steps 4 and 5, we had a second author review the papers. One author also did a second review of all borderline papers. To evaluate the quality criteria, all papers were reviewed by the first author as well as one of the other authors. Finally, we ended with 107 papers for data extraction and analysis, as listed in Table 11 (Appendix A).

Most of the papers included were published in peer-reviewed conferences (74\%). ACM and IEEE channels were most common; however, there were also some learning technology and general education venues present. There has been a rise in the number of publications on these topics since the first paper in 1994, with a significant jump in the mid 2010s and with 63\% of the included papers being published after 2015. The papers originate from all parts of the world; however, many papers referenced research done on the American continent $(n=49)$, and most of these were from 
the US or Canada. Otherwise, 27 papers originated from Europe, 12 from Asia, 12 from Australia or New Zealand, and 2 from Africa. Last, there were 5 multinational papers, ranging from two countries included to 10 .

3.2.1 Data Extraction and Analysis. Data extraction was done by coding each paper according to nine variables [86]. The results of this coding process were then further analyzed to answer the research questions. Table 4 describes these variables and how they address the research questions. Some variables were accompanied by predefined categories, and some were based on noting or copying excerpts from the texts. For these open categories, we made sure only to extract data that was stated in the paper. For example, when extracting data on teaching implications, we only noted the actual implications mentioned in the paper, not what our opinion on potential implications was. A full overview of extracted data can be found at https://doi.org/10.18710/JQX7NW.

The first author coded all the papers, while the remaining authors coded a set each, providing double coverage of all the papers. The authors paired up to review their data extraction, identify differences, and agree on the final version. In instances where there was disagreement between these two authors, a consensus was reached by discussion. Certain factual fields were checked against the paper, while more subjective fields, such as study behavior, were merged in a way to include the most details.

The analysis was performed using non-statistical methods following the nature of the variables. Where needed, we categorized and counted the extracted data. For example, behaviors were categorized and grouped following the taxonomy presented in Figure 1. In the following sections, we detail this analysis, summarize the results, and describe the findings for each research question.

\section{DEFINING STUDY BEHAVIORS IN COMPUTING EDUCATION (RQ1)}

This section describes the results relating to the first research question: How are study behaviors defined in computing education research? When extracting the study behavior aspects of the selected papers, we placed the study terms used in the papers into behavioral constructs following the taxonomy presented in Figure 1. When analyzing the data further, we combined the research goals, data collection methods, description of behavior, main results, and implications to determine what behavioral constructs were discussed and how they were defined.

\subsection{The Study Behaviors Identified}

After extracting the various study terms from the selected papers, we mapped them into constructs according to the taxonomy. For example, papers that referenced deep and surface approaches to learning were placed under "process." Many papers, though, used terminology that was inconsistent with the definitions presented in Section 2. For example, "study habits" was used to describe many behavioral constructs that would be placed under tactics or skills according to our taxonomy. In one source, the term "learning habit" is used to describe time spent on assignments and the number of submissions, posts, and videos watched in an online learning system [66]. In this case, one could argue that study time, or time engagement in a study activity, should be categorized as a habit; however, the use of videos and posts would be considered a study tactic. In Hedin and Kann [70], the focus was on study skills, listed as preparing before lectures, smart note-taking, repetition, planning the upcoming week, maintaining a study diary, reading the course literature in three steps, and not procrastinating. However, most of these constructs are tactics, except for planning and procrastination, which are terms under "strategies." In other words, a central finding is that terminology use is inconsistent. The same terms are used to describe different aspects of studying. In the following sections, we review the findings for each of the taxonomy constructs. 
Table 4. Description of Data Extraction Variables and the Connection to Research Questions (RQs)

\begin{tabular}{|c|c|c|c|}
\hline Variable & Description & Categories & RQs \\
\hline Research/educational goal & $\begin{array}{l}\text { What was the goal of the research? } \\
\text { In what way (if any) is the research re- } \\
\text { lated to performance and/or learning } \\
\text { outcome? }\end{array}$ & Write down & $1 / 2$ \\
\hline Research questions & $\begin{array}{l}\text { What were the research } \\
\text { questions/hypothesis? }\end{array}$ & $\begin{array}{l}\text { Research questions } \\
\text { Hypotheses } \\
\text { Lessons learned }\end{array}$ & 2 \\
\hline Data collection & $\begin{array}{l}\text { Type of data source/collection meth- } \\
\text { ods }\end{array}$ & $\begin{array}{l}\text { Survey } \\
\text { Questionnaire } \\
\text { Validated questionnaire } \\
\text { Log-data } \\
\text { Submission data } \\
\text { Interviews } \\
\text { Focus groups } \\
\text { Exam results/grades } \\
\text { Other: write down }\end{array}$ & 1 \\
\hline Behavior & $\begin{array}{l}\text { What aspects of study behaviors were } \\
\text { reported on, and how are they mea- } \\
\text { sured? }\end{array}$ & Write down & $1 / 2$ \\
\hline Main results & What were the main results? & Write down & 1 \\
\hline Teaching implications & $\begin{array}{l}\text { What were the teaching implications } \\
\text { (if any)? }\end{array}$ & Write down & 3 \\
\hline Sample population & What level was the research done in? & $\begin{array}{l}\text { Introductory level } \\
\text { Undergraduate level } \\
\text { Graduate level } \\
\text { All levels } \\
\text { Other: write down }\end{array}$ & 3 \\
\hline Educational context & $\begin{array}{l}\text { What was the education context for } \\
\text { this research? }\end{array}$ & $\begin{array}{l}\text { Campus } \\
\text { Online } \\
\text { Blended } \\
\text { Mixed (students from both) }\end{array}$ & 3 \\
\hline Pedagogical context & $\begin{array}{l}\text { What was the pedagogical context for } \\
\text { this } \\
\text { research }\end{array}$ & $\begin{array}{l}\text { Traditional } \\
\text { Peer Instruction } \\
\text { Flipped } \\
\text { MOOC } \\
\text { Other: write down }\end{array}$ & 3 \\
\hline
\end{tabular}

4.1.1 Process. While the term "study process" refers to the level of cognitive engagement in study activities, it is also commonly used to describe the different stages and events in studying $[11,141]$. In total, 24 of the papers included aspects relating to the study process, referencing the student approaches to learning (SAL) framework or the learning styles framework, as listed in Table 5. Within the SAL framework, deep, surface, strategic, and achieving dimensions are in use, but the Biggs's Study Process Questionnaire (with only the deep/surface dimensions) is the most common. Within learning styles, we found examples of Felder's dimensions (active/reflective, 
Table 5. Overview of Papers Referencing the Study Process

\begin{tabular}{llc}
\hline Process & \multicolumn{1}{c}{ Papers } & Count \\
\hline Student approaches to learning & {$[5,24,49,56,62,74,93,96,99$,} & 20 \\
& $101,108,114,117,118,126,144$, & \\
& $155,168,172,173]$ & \\
Learning styles & {$[22,23,34,112]$} & 4 \\
\hline
\end{tabular}

Table 6. Overview of Papers Referencing Study Strategies

\begin{tabular}{llc}
\hline Strategies & \multicolumn{1}{c}{ Papers } & Count \\
\hline Affective constructs & {$[24,34,54,62,63,65,68,85,91,103,122,124,136,143,151]$} & 15 \\
Time management & {$[2,6-8,40,45,51,59,70,81,95,105,161,166]$} & 14 \\
Strategies & {$[1,28,42,48,63,77,90,95,146,149,159,160]$} & 12 \\
Self-regulation & {$[5,25,46,61,78-81,122,169]$} & 10 \\
Motivation & {$[1,61,65,68,125,166,172,173]$} & 8 \\
Metacognition & {$[28,32,48,69,75,81,125,151]$} & 8 \\
Programming Strategies & {$[33]$} & 1 \\
\hline
\end{tabular}

sensing/intuitive, visual/verbal, sequential/global) [22, 23] and Kolb's learning cycle (concrete experience, reflective observation, abstract conceptualization, active experimentation) [22, 23, 34, 112]. In reference to the substantial criticism of learning styles described above, it is important to note that the four papers referencing learning styles were published between 1999 and 2009, indicating that learning styles are no longer a part of computing education research literature.

4.1.2 Strategies. In total, 68 references were made to study strategies in the selected papers, as further specified in Table 6. Some papers referenced several aspects of strategies and therefore appear more than once. Furthermore, some papers only referenced strategies in a general wayfor example, describing the application of tactics [160] or cognitive routines [48]. Several papers used the term "strategy" but were referring to the study process $[172,173]$. One paper talked about programming strategies, referring to specific planning strategies related to programming problems, such as "finding an average through several sub-algorithmic plans such as a triangular swap" [33].

A large number of the referenced strategies were related to metacognition and self-regulation, but as Prahter et al. [130] established, it can be challenging to distinguish between these terms. To differentiate and specify the terminology landscape, we chose to keep the underlying terms visible in Table 6 . The seven papers that referenced metacognition generally used the term to describe monitoring [69] or reflecting [28] on one's own study strategies, or those papers used the umbrella term "metacognitive factors" [32]. Within self-regulation, we found the terms "organization," "direction," and "time management." Within time management, two papers referenced pacing study activities as a specific management aspect $[155,161]$. Furthermore, three papers explored the starting time of assignments as tasks, both discussing starting early [2, 45] or late [59]. Start and finish times, which are closely linked to procrastination, were the focus of seven papers $[8,40,51,70,81,95,105]$.

Last, we grouped personality, epistemological beliefs, attitudes, motivation, grit, and confidence into affective constructs [70,152], also referred to as non-cognitive factors [136, 143]. There seems to be slight disagreement regarding whether these terms are aspects of metacognition or whether they should be viewed independently. For example, motivation and epistemological beliefs can be 
Table 7. Overview of Papers Referencing Study Habits

\begin{tabular}{llc}
\hline Habits & \multicolumn{1}{c}{ Papers } & Count \\
\hline Time engagement & {$[11,24,27,41,42,46,51,58,65,66,73,75,76,84,89,94,108,121$,} & 31 \\
& $122,125,127,139,141,142,154,156-158,162,164,171]$ \\
Habits & {$[4,20,24,27,31,42,45,46,66,70,80,81,91,120,138-140,167]$} & 18 \\
Attendance & {$[1,19,24,31,89,108,121,169]$} & 8 \\
Programming habits & {$[2,154]$} & 2 \\
Life & {$[158]$} & 1 \\
Social networks & {$[59]$} & 1 \\
\hline
\end{tabular}

found under self-regulation and metacognition in Prather et al. [130]. However, for the purpose of this mapping, there seems to be an agreement in the definitions that these are all aspects of cognitive control. Affective constructs were often one of several aspects being researched or used to explain differences in performance. For example, Haungs et al. [68] describe a course development where motivation and confidence were two of several variables investigated to improve success and retention. A different example is Tolhurst [151], who specifically investigated the effects of a course revision on epistemological beliefs.

4.1.3 Habits. An overview of study habits identified in the included papers can be viewed in Table 7. In the review of the included papers, it was challenging at times to classify the reported behaviors as habits, since the authors often referred to what we have defined as strategies. We, therefore, made a distinction between intention and action when determining if a reported behavior should be considered a strategy or habit. Whereas strategies refer to cognitive control (i.e., planning, monitoring, and intention), habits depict what students actually do. In the article by Foo and $\mathrm{Ng}$ [49, p.2], study habits are defined as "the behaviors associated with studying (excluding methods used to learn or utilize academic material) such as time management and anxiety reduction," a definition that is more in line with the cognitive perspective of study strategies. An illustrative example of this distinction is the difference between time management (strategy) and time engagement (habit). Time management refers to the planning and intention of studying, often relating to when students study. Time engagement [89], however, refers to when the students did study and how much-for example, how much time students spent on an activity [24, 41, 46, 108, 139, 157], time spent in a system [142], time spent coding [70], or time spent before or after a class [171]. Similarly, attendance is a study term concerned with what a student has actually done and was the focus of eight papers $[1,19,24,31,89,108,121,169]$. Some papers also focused on change in habits over time [46, 70] or the effect of an intervention such as an academic enhancement program [42], or supplemental instruction $[45,81]$.

A common theme in the papers on study habits was the discussion of good and bad behaviors. In some papers, habits were referenced as "good" or "bad" [2, 20, 27]. However, some papers also referenced "habits leading to success" [24] or "harmful habits" [8]. Not all papers were systematic in describing what good and bad habits are, which is arguably a relative concept. Some papers define bad habits by looking at how they relate to performance [27, 41, 121] or predict success [4, 45].

Two papers referenced programming habits specifically, with one relating to how novice programmers write code [154] and the other focusing on time spent programming [2]. In that latter paper, Allevato and Edwards [2] used time spent programming, among other variables, when evaluating the effects of extra credit on procrastination behavior. Only one paper specifically mentions social aspects of study habits and views participation in social networks as a habit [59]. 
Table 8. Overview of Papers Referencing Study TactiTcs

\begin{tabular}{llc}
\hline Tactics & \multicolumn{1}{c}{ Papers } & Count \\
\hline Techniques & {$[7,8,48,51,54,56,70,76,99,113,120,139$,} & 14 \\
& $160,162]$ & \\
Resources & {$[47,48,54,66,99,103,120,127,156,167]$} & 10 \\
Social & {$[19,63,66,73,96,141,142,157,162]$} & 9 \\
Trying & {$[7,8,20,42,48,58,141,142,162]$} & 9 \\
Preparations & {$[70,111,160,167,171]$} & 5 \\
Coding & {$[45,47,59,154,170]$} & 6 \\
Help & {$[69,95,99,114,160]$} & 5 \\
\hline
\end{tabular}

4.1.4 Tactics. In total, there were 57 references to tactics in the included papers, with several papers mentioning more than one tactic. When distinguishing a habit from a tactic, we considered the origin and consistency of the behavior. For example, attendance is considered a habit but taking notes a tactic. We further grouped the various tactics into seven categories, as illustrated in Table 8. For the previous constructs, the categorization was based on theoretical concepts, but for tactics, we found it more useful to create new groups. First, we made a distinction here between using various resources, such as videos [48, 66, 103, 127, 167], books [99, 167], and hints [47], and techniques, such as memorization [6, 139] and note-taking [70, 160]. Furthermore, the category of trying includes tactics related to attempting assignments [48, 142], solving many problems [7, 42], and retaking quizzes $[20,162]$, often tracked with log-file data. In contrast to most of the other behavior levels social interactions [19, 66, 73, 96, 141, 142,157] and collaboration $[63,162]$ are two frequently mentioned tactics. The help category includes asking questions [99, 160] and help seeking behavior [69, 95], and the preparation category refers to preparing for lectures [167], tests [160], and classes [70, 111, 171]. Last, the coding category relates to specific tactics used when programming, such as using auto-complete [154], compilation frequency [45, 47, 154], debugging, and use of version control systems [170]. Vihavainen et al. [154] for example, looked at how novices tackle their first lines of code in an IDE and found that students tend toward three tactics: writing code from left to right, using auto-complete, and copying and pasting.

\subsection{Theoretical Frameworks Used}

In addition to categorizing the behavior terms and mapping them into the proposed taxonomy, it is also interesting to note where the definitions in the selected papers came from. Fewer than a third of the papers were grounded in established theoretical frameworks $(n=32)$. The most common framework used was Biggs's study process $(n=11)$. Some papers also relied on a validated questionnaire used in defining behaviors; however, the framework behind the questionnaire was not necessarily explored beyond the results $(n=14)$. In total, 15 papers reported their results by using a validated questionnaire within the learning and behavior domain. In addition, a substantial number of papers proposed their own definitions for what qualifies as a study behavior $(\mathrm{n}=30)$ or based their definition on the data $(n=24)$. For example, based on log data from a MOOC platform, Sheshadri et al. [142] looked at study habits via time engagement, defined as "study sessions as consecutive sequences of study actions that occur between breaks for food or sleep." Similarly, one paper defined study habits as time spent in the system, number of submissions, and number of posts and videos watched [66]. In general, time management and engagement were often used as indicators of strategies and habits. Last, seven papers did not reference any definitions. For 
Table 9. Overview of How Papers Used Study Behaviors

\begin{tabular}{|c|c|c|}
\hline Decrease/reduce & Papers & Count \\
\hline Dropout & {$[1,5,11,74,89,125,169]$} & 7 \\
\hline Failure rates & {$[45,80,160]$} & 3 \\
\hline Procrastination & {$[40,62]$} & 2 \\
\hline Bad behavior & {$[2]$} & 1 \\
\hline \multicolumn{3}{|l|}{ Improve/enhance/increase } \\
\hline Learning & $\begin{array}{l}{[28,73,76,78,79,81,90,93,95,96,105,114,} \\
127,139,140,155,164,166,167,170]\end{array}$ & 19 \\
\hline Study behavior & {$[8,42,49,56,121,122,146,151]$} & 8 \\
\hline Performance & {$[6,7,31,32,41,162,172,173]$} & 8 \\
\hline Retention & {$[19,70,85,138,159,161]$} & 6 \\
\hline Engagement & {$[48,61,84,118]$} & 4 \\
\hline Experience & [4] & 1 \\
\hline Online learning & [79] & 1 \\
\hline Programming skills & {$[33,63,111]$} & 3 \\
\hline \multicolumn{3}{|c|}{ Learn about/understand/identify } \\
\hline Study behaviors & $\begin{array}{l}{[20,22-25,46,59,99,117,120,126,141,149,} \\
168,171]\end{array}$ & 12 \\
\hline Learning & {$[22,23,126]$} & 3 \\
\hline Online learning & {$[51,101]$} & 2 \\
\hline Programming learning & {$[65]$} & 1 \\
\hline \multicolumn{3}{|l|}{ Predict } \\
\hline Performance & {$[34,58,68,75,94,136,142-144,157,158]$} & 11 \\
\hline Identifying students at risk & {$[47,69,77,154]$} & 4 \\
\hline \multicolumn{3}{|l|}{ Various } \\
\hline Improving a tool/system & {$[27,54,91,108,113,156]$} & 6 \\
\hline Culture/gender diversity & {$[103,147]$} & 2 \\
\hline Transition to university & {$[66,112]$} & 2 \\
\hline Supporting teachers & {$[124]$} & 1 \\
\hline
\end{tabular}

example, Carpenter and McCusker [20] mention retaking quizzes as a way to reinforce good habits but do not elaborate further.

\section{THE ROLE OF STUDY BEHAVIORS IN COMPUTING EDUCATION (RQ2)}

This section describes the results relating to the second research question: In what ways are study behaviors included in computing education research? In this analysis, we used the variables of research/educational goal, data collection, and study behaviors. By investigating the goal of the various papers, we found why study behaviors were used as well as how they were used. Inspecting the research/educational goal, we found that most papers had one of four goals: (1) decrease or reduce undesired outcomes; (2) improve, enhance, or increase desired results; (3) learn more about, understand, or identify something; or (4) predict behaviors or events. These goals are illustrated in Table 9.

A majority of the selected papers used different study behavior constructs to explain other aspects of education, such as performance, drop-out, or prediction $(\mathrm{n}=72)$. For example Benda et al. 


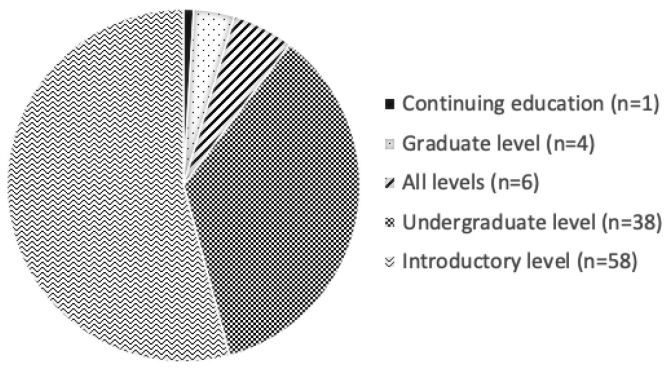

(a) Sample population

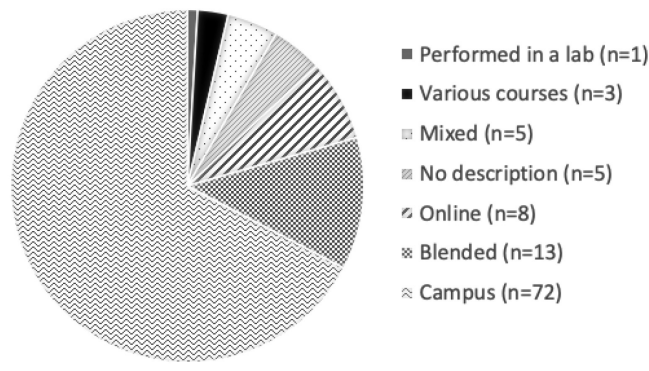

(b) Educational setting

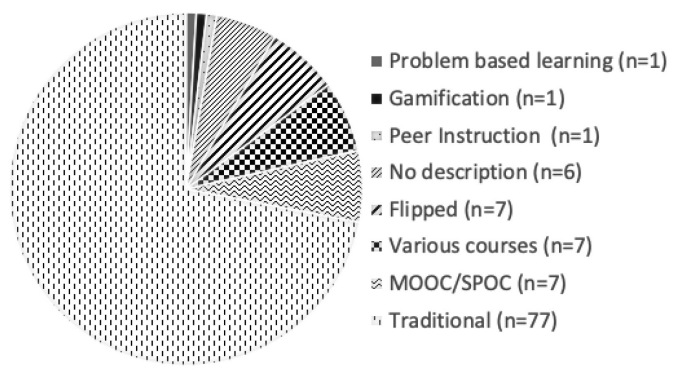

(c) Pedagogical context

Fig. 3. Summary of educational context parameters.

[11] investigated why online computing students drop out, using time engagement as an explanatory variable. Similarly, Chinn et al. [24] focused on identifying study habits that lead to success. Several papers related behavior to performance, such as Höök and Eckerdal [76], who investigated habits, and Hedin and Kann [70], who looked at strategies and tactics. Common for most of these examples, and most of the explanatory papers in general, is that the behaviors were one variable of many in the analysis or discussion sections [4, 46, 80, 138, 139].

A minority of the included papers viewed study behavior as the dependent variable, where the goal was to explore these behaviors $(n=35)$. In these exploratory papers, it was common to investigate how various interventions affected certain behaviors, to model behaviors for use in online learning tools or the study process across student groups [49]. Sheard et al. [140] adopted a holistic focus on study habits by exploring where, when, how, and with whom computing students studied, but such an approach was less common. Regarding the inclusion of behaviors in the analysis, it can be concluded that using behaviors as an explanatory factor is more prevalent than exploring behaviors. Furthermore, there is a focus on improving learning by decreasing or increasing various behaviors; however, the definition of "better" is somewhat unclear.

\section{EDUCATIONAL CONTEXT AND STUDY BEHAVIORS (RQ3)}

This section describes the results of the third research question: What is known about the role of educational context in shaping study behaviors? For this analysis, we used sample population, educational context variables, and pedagogical context variables. When considering the educational context, it is valuable first to examine the sample population, and in this case, the population's level of education. A majority of the papers used students at the introductory level $(n=58)$ - that is, first-year courses (CS0, 1, and 2). A somewhat typical example is the paper by Gomes et al. [61], who investigated connections between study strategies and performance in an introductory 
programming course. A different example is the multi-national investigation of Simon et al. [144] into cognitive, behavioral, and attitudinal factors that influence entry-level student's success in learning programming. Furthermore, Figure 3(a) shows that 38 papers included students at the undergraduate level; 4, students at the graduate level; and 6, students at various levels. Last, 1 paper presented research done on students enrolled in continuing education [11].

When it comes to the educational setting in which the research was performed, the majority of papers described a campus-based environment $(n=72)$. Some were done in a blended environment $(\mathrm{n}=13)$ or fully online $(\mathrm{n}=8)$. Only one paper presented research performed in a laboratory [127], indicating that behaviors are mainly researched in a natural setting. Additionally, some papers described mixed environments, where some students attended on campus simultaneously with students online $(n=5)$. For example, Petersen et al. [125] investigated reasons for dropping out of a multi-campus CS1 course with students at different campuses and online. As many as seven papers did not describe the setting in which the research was performed, and two studies were done in multiple courses where the educational setting was not described. For example, Halde et al. [65] used machine learning to investigate the impact of study strategies and habits on performance for students across the computing department. These findings are summarized in Figure 3(b).

Figure 3(c) summarizes the pedagogical context for the included papers. The predominant pedagogical context identified in the selected papers was a traditional design $(n=77)$, meaning that lectures and labs were primary components. While the exact learning design of these courses may have had significant variation in how lectures and labs were conducted and whether labs counted toward the grade, all pedagogical contexts with a heavy focus on lectures and labs were coded as "traditional" unless the paper described alternative pedagogical approaches that positioned it in another category. For example, Manley and Urness [103] compared the use of video lectures to in-person lectures in a course with quizzes and lab exercises. Some papers described MOOC and SPOC contexts $(n=7)$, and some described the program level or included several courses, making the pedagogy difficult to describe $(n=7)$. Flipped classroom designs were the focus of seven papers, such as Lin and $\mathrm{Wu}$ [96], who explored social interactions in a flipped classroom setting. In seven papers, the pedagogical context was not described; however, that omission was often because the focus on the paper was on specific tools [156], techniques [144], or teacher perspective [124]. Last, a few papers examined specific pedagogical contexts, such as Ma's [101] investigation of students" approaches to learning in problem-based learning.

The findings on the relationship between study behaviors and educational context in the included papers are somewhat ambiguous. The learning activities and interventions proved difficult to categorize, because the various papers had different goals and focuses. The main observation is that most papers examined general study behaviors, sometimes with a specific intervention, but often without one. It can be concluded, however, that introductory-level education is most prevalent, as is traditional pedagogy in campus-based environments. Concurrently, it was observed that there are discrepancies in the level of detail in the descriptions of educational and pedagogical contexts, making it hard to make further inferences. The next step is to further solidify the connection between various behaviors and the specific educational design parameters. Table 10 lists some proposed relations between the study behavior terms and educational design parameters, including references to example papers found in the current review.

\section{DISCUSSION}

In this section, we discuss the results, identify contributions, and present some observations and recommendations that follow from our review. We take this opportunity to summarize the important findings for each of the research questions and discuss the relation between them, building on the theoretical perspectives in Section 2 and extending the taxonomy of study behaviors. 
Table 10. Potential Link between Study Behaviors and Educational Design Parameters

Behavior Educational design parameters Potential impact factors and examples

Process Program, semester, and course design The study process is hard to influence; however, research has found that approaches to learning do develop over time, suggesting that the educational design parameters have an effect [98]. The number of courses per semester, parallel versus modular approaches, weight and alignment between courses are some aspects to consider $[125,151]$.

Learning activities and assessment The holistic design of each year, the combination of courses and teaching and learning activities play a role [84].

Strategies Learning outcome goals

Study strategies are also challenging to influence through educational design. However, including learning goals directed toward developing metacognitive skills in addition to content knowledge might support students in this regard.

Specific training

Offering courses and training targeted toward the development of study strategies is one potential impact factor (e.g., programs integrating courses and academic-enhancement programs $[32,42,70,81])$.

Habits Scheduling of organized activities The scheduling of organized activities can provide useful scaffolding for the development of study habits [80,84].

Mandatoryness/participation The implementation of mandatory participation is a tool educators can especially use to influence habits. However, one should be mindful of the holistic design and ensure variation and balance [164].

Tactics Learning activities and assignments

When designing learning activities and assessment, one can consider what tactics students might need to master to broaden their studying toolkit $[111,162]$.

IDE and technology choices Similarly, regarding choosing IDEs and technologies for use in computing courses, there is room for broadening the students' abilities (e.g., use of version control systems, webbased platforms, and professional IDEs [154]).

\subsection{Defining Study Behaviors in Computing Education (RQ1)}

The investigation into how study behaviors are defined in computing education revealed two main findings. First, the review found that the same terms are used to describe substantially different 
study behaviors and that the lack of standard terminology makes it difficult to compare findings from different papers. This finding is in line with research from other disciplines on the fragmented domain of study behavior definitions and terminology [152]. Educators and researchers should be mindful of this lack of unity and provide clear definitions in future research papers [130]. Second, these definitions are mainly based on data or self-described characterizations. Of all the papers, 75\% did not define their terminology clearly, or they used self-defined terms where more established definitions were already available. The use of and development of domain-specific theories and models is an area where computing education research can grow. The work by Prather et al. [130] is a good example of a systematic contribution to bridging the gap between theories on cognitive control and programming education. This review found that the use of theoretical frameworks was often limited to the inclusion of a questionnaire or used as an explanatory element in the computing education field.

In support of this future work, we expanded the taxonomy in Figure 1 to include the study terms identified in the reviewed papers. This extended taxonomy is depicted in Figure 4. In the following, we further discuss the definitions and grouping of the included study behavior terms with regard to the perspectives in Section 2.

- Process: For the process behavior construct, two study terms were identified: SAL framework and learning styles. We included learning styles in the taxonomy, because it does not aim to model or moderate anything; however, we urge researchers and educators to be aware of the substantial critique of learning styles [115]. With regard to the SAL framework, we found that deep/surface approaches to learning was a commonly used variable; however, SAL theory is not often discussed. Questions for further exploration include what deep and surface approaches to learning mean in computing education and what insights they can give computing educators about the quality of learning [26, 104].

- Strategies: Strategies were defined using many different study behavior terms, and in the extended taxonomy, we include metacognition, self-regulation, time management, and affective constructs. Time management was the most referenced concrete aspect, perhaps because it is somewhat easily measurable. Affective constructs and motivation were also common terms, indicating that many papers attempted to include more personal aspects. We also revealed attempts to differentiate general strategies and programming strategies, which could be an avenue to pursue further.

- Habits: Within habits, we include time engagement, attendance, social networks, and balancing student life. The two latter terms were only referenced in one paper; however, social aspects [128] and balancing life [119] are important aspects of studying. Additionally, we found that the habits construct was the most loosely defined study behavior construct, often referring to strategies, specifically time management. Similar to strategies, we found specific mentions of programming habits. Further research could explore the notion that computing requires specific study strategies and habits.

- Tactics: For tactics, we include the seven groups of individual learning tools identified in this review. We believe there are more tools but hope the categorization may be valid nevertheless. It is within this construct that we identified the most computing-specific terms, grouped under "coding." However, the tools of social connections and "trying" are also linked to many pedagogical approaches in computing education, such as project and team-based learning [18] and pair programming [163].

To summarize, the contribution of the findings related to the first research question is the extended taxonomy of study behaviors in computing education (Figure 4). The taxonomy is based on theoretical definitions but takes into account many data-driven approaches. Similar to the review 
Behavior

Any actions students make when preparing for, or taking part in, study activities.

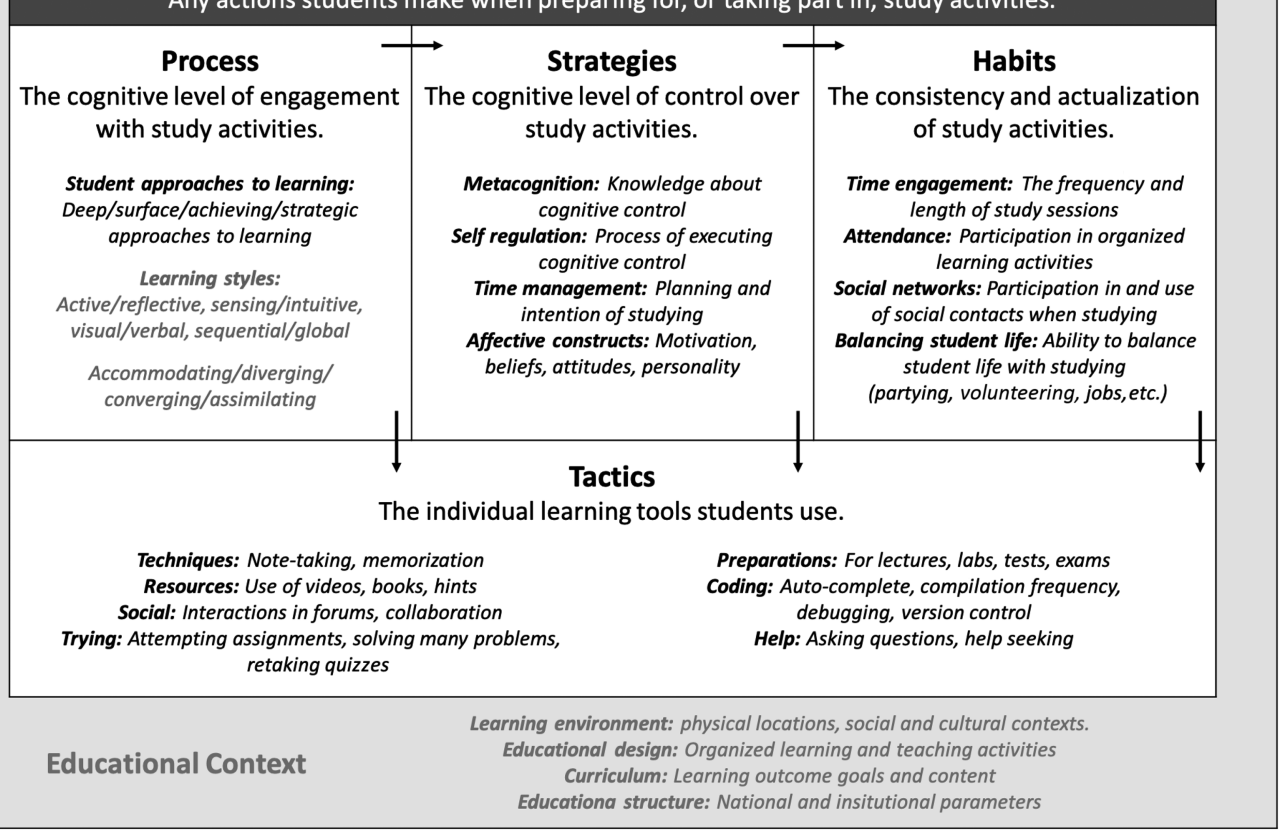

Fig. 4. Extended taxonomy of study behaviors for computing education.

by Szabo et al. [148] of learning theories in computing education, this article provides a synthesized overview and associated exemplars to improve the understanding of study behaviors, including how they relate to the educational context. Future research and practice can use this framework to identify terms when designing research projects or educational innovations, and it can serve as a tool for understanding and interpreting published research. In the discussion of the remaining research questions, these connections are explored in more detail.

\subsection{The Role of Study Behaviors in Computing Education (RQ2)}

The investigation into what ways study behaviors were included found that most papers used study behaviors to explain other student-related aspects, such as academic performance, engagement and dropout. Consequently, a minority of the included papers explored study behaviors. Considering the prevalence of inconsistent terminology, it is challenging to infer any trends or conclusions as to the role of specific study-behavior constructs. Reviewing Table 9, it is apparent that there were substantially more efforts published aiming to improve, enhance, or increase positive aspects of studying than to decrease or reduce negative aspects. Furthermore, it was not uncommon to read about "good" and "bad" study strategies, habits, and tactics in papers about different educational designs and innovations. To our knowledge, there is no established consensus distilling good, successful study behaviors. As several researchers have pointed out, we must be wary of developing "folk conclusions," whereby certain hypotheses are widely accepted as truths despite lacking empirical verification $[67,132]$. Although all educators may have an idea of what good and bad behaviors are, such a vague and coarse categorization is not helpful for research. Furthermore, determining whether a behavior is good, successful, positive, or improved relative to a previous behavior depends on one's perspective. Indeed, the assessment of a behavior depends 
on whether the goal is for students to perform well on tests, learn the content, have a positive experience or hand in assignments on time. This review provides examples of all such perspectives as well as contradictory results. For instance, procrastination behavior is generally seen as a "bad strategy" [40, 62]. However, Goldstein et al. [60] found that procrastination does not necessarily decrease performance; it is the consistency of behaviors that matter. A student who usually starts assignments late may perform at the same level as one who usually starts early, but when an early starter starts late, the performance declines.

We believe it will be challenging to conclusively define good or bad computing study behaviors, even with more research on the topic. Perhaps a better approach for researchers and educators going forward is to focus on how knowledge about how students do study can help educators support students in developing effective study behaviors. All such discussion should of course keep in mind that the student is a complex being and that there is major individual variation between students.

In addition, while this review provides many examples of using study behaviors to explain the "quantity of learning," another perspective to explore is the quality of learning [44]. To do this, the computing education research community needs to place additional focus on exploring study behaviors. Only one-third of the reviewed papers aimed to identify study behavior, and only a few included perspectives across courses. Supporting students in their ability to learn how to learn is a potential next step for the computing education community. A holistic approach to student learning-considering more aspects of study behavior and educational context together-can be one important step. An additional avenue to pursue is including aspects of study behavior as indicators of success, broadening the perspective of academic success beyond grades and test results.

Another important finding in this review is that study time is a common variable to evaluate study behavior. Together, time management and engagement were by far the most common study terms, used in 44 of the included papers. However, study time is a debated metric. Some papers report that time spent studying can predict performance when seen in relation to other variables, such as previous experience and the learning environment [107, 119, 128, 137, 145]. These papers all emphasize the context, and that study time alone does not seem to be a good indicator of performance. Similar concerns have been raised about the quality of study time data as well as defining what it means to study computing specifically [135]. Moreover, the unresolved question of what study time data can tell us is supported by the current review-namely, that most behaviors are defined based on data and not on theoretical or established definitions. For example, it is interesting to consider what we can learn from timestamp data. As established, there is a theoretical difference between time management and time engagement, where the former is an aspect of cognitive control and the latter an actualization of said control, and timestamp data alone provides limited insight into the cognitive perspective.

The contribution of this section is an overview of where the focus in the field has been. Study behaviors in computing education have mainly played a supporting role in the investigation of academic performance [71, 100]. There are opportunities to improve our understanding of student learning by expanding the role of study behaviors in research and practice. In this work, the taxonomy can play an important role in setting the boundaries for coherently defining study behaviors across the community. Accordingly, we emphasize that this taxonomy is not a model for students' behaviors, only a road-map to understand them.

\subsection{Educational Context and Study Behaviors (RQ3)}

Regarding the third research question, which explores the relation between educational context and study behaviors, the main finding is related to what was present in the reviewed literature 
and what was missing. We found that research on study behaviors in computing education has been overwhelmingly focused at the undergraduate level, with a specific focus on introductory programming courses. The research has also mainly looked at study behavior under "traditional" teaching approaches in on-campus settings-that is, courses with a typical weekly progression of lectures and assignments. The prevalence of traditional designs is not surprising, considering this has been the dominant approach to educational delivery [100], but with increasing variation in approaches and settings, there is a need for more research on the alternatives. For example, it would be interesting to see more research on graduate-level study behavior and comparative approaches investigating whether there is a difference between levels and why. As most of the reviewed papers only provide snapshots of students' behavior in one particular course, it would be particularly interesting to see longitudinal approaches following groups of students throughout their studies to investigate how their study behaviors and awareness thereof develop with increased study experience. Latitudinal approaches (comparing behavior in several courses taken by the same group of students) could also be of interest to see the extent to which they adopt different behaviors in different courses and why. In these broader research approaches, we could also further explore the role of informal learning [13] and social interactions [9], two areas that have been largely overlooked in the research. Such research might also help illuminate some of the relationships between educational contexts and study behavior, which are currently unclear.

An important factor not present in most of the published work is the institutional structure, social context, and cultural context surrounding education. One concrete example is the age of the students and their level of independence. In Nordic countries, students enter higher education at the age of 19 , while in the US, they may be 17 years old. When discussing study behavior, there is a large difference between 19 and 17, and when further considering the difference in the level of independence for these students, this divide increases. These social factors play an important role for students in their learning [150]; however, such factors are not present in discussions on computing students' study behavior. In the detailed taxonomy in Figure 4, we include balancing student life, where, for example, the presence of part-time jobs is a factor. Only one paper in the review included such an aspect of student life outside of academics [158]. To be able to account for such differences, there is a need to adopt a standard for including and describing educational design parameters at an established level of detail. These are variables outside of educators and researchers' control; however, we argue that they should be a factor considered when interpreting results or designing interventions.

This third research question makes the valuable contribution of revealing the importance of educational context. In the taxonomy, this emphasis is illustrated by adding educational context as an encompassing construct with specific terms. Altering the educational context can change the quality of student learning [110], and some concrete examples of the relation between different educational contexts and the study behavior constructs are summarized in Table 10. The educational contexts present in the published works range from very large classes to small student groups in online, blended, and on-campus settings. Many of the included papers, though, lacked descriptive detail about the educational context.

\subsection{Implications}

For educators, the value of this review lies mainly in the collection and mapping of research on study behaviors in computing education. The fragmented domain limits our ability to draw conclusions or make recommendations for educators to best support effective study behaviors. We have found some examples of how explicitly teaching students about study behavior, such as time management and planning, results in increased performance and experience [32, 42, 70, 81]. Furthermore, there does seem to be room for action when it comes to designing and structuring 
courses and programs to support students as they learn to learn, as explored in Table 10. Finally, we hope that the extended taxonomy presented in Figure 4 can serve as a guide for educators seeking to understand how students do (or do not) study.

For researchers, we outline the domain of study behaviors and identified some areas for future research. In addition, we propose a taxonomy for study behavior constructs and terms in computing education, which can be used to inform future research in the field. As with any proposed theoretical or conceptual frameworks, we expect it will need further development and validation [102]. Based on this review, we would like to summarize some recommendations for future researchers:

- Provide clear definitions of the study behavior constructs being researched.

- Avoid turning to self-defined definitions where theoretical frameworks are available.

- Refrain from making assumptions about what behaviors are good or bad.

- Be specific when describing the educational context of the research.

In addition, there are some gaps in the research and possible future research questions:

- Exploring the computing discipline specifically: Are computing students different than others? Do computing topics imply or rely on specific study behaviors? Are the methods and variables used to research study behaviors in computing appropriate and accurate?

- Expanding the perspectives on educational and pedagogical contexts: What is happening outside and between courses? How are students developing their study behaviors throughout their studies? Are there educational designs or teaching approaches that can support students' study behaviors?

- Exploring the roles of informal and social learning in computing: What are students doing outside of organized, formal learning? What social behaviors are important for learning computing?

Although the measurement of study behaviors in computing education research was not the main focus of this systematic review, we cannot avoid addressing how behaviors are being researched and the link to theory. Considering the prevalence of self-defined, data-driven definitions and the reliance on questionnaires found in the reviewed works, it seems to be the data points that drive research on study behaviors rather than theory. This approach has implications for future practice and research, and it is important to raise the question of whether we measure what we think we are. As Prather et al. [130, p. 11] point out, "self-report measurements of cognitive control, such as the MSLQ, often measure what students think they do, rather than what they actually do." The limitations of self-reported measurements are one thing, but we must also consider how researchers interpret data from other sources. Computing education has the benefit of access to much log-file data on students; however, we must be careful in what we can infer from such data [130]. There have been some interesting developments on how log-file data can be used to identify cognitive processes, and calls have been made for further development into identifying effective indicators across disciplines [153] and for dealing with the invisible activities that happen in breaks of data [94]. There are also some developments in the field of learning analytics and multi-modal data in connection to cognitive processing that will be interesting for computing education to follow [21,55]. With the abundance of data available to computing education researchers through compilers, version control systems, and IDEs, computing education research is well situated to be a part of this development.

\subsection{Limitations}

The main limitations of this review are biases in the selection, search, and data extraction. The choice to limit the review to English publications may have led to the omission some papers and 
may be a partial explanation for why North America and Australia/New Zealand were found to have larger output relative to population. Some researchers in various countries may treat computing education research as a side topic, whereas their main research is primarily technical computer science. While focusing on English language venues for their main research, they might, to some extent, present the education-related works in lower-prestige national venues. However, if we were to include papers in the few non-English languages that we also understand, then it would likely have led to more bias, not less, and would have reduced the review's repeatability for researchers of different language backgrounds. The choice to focus on English is commonly made for systematic reviews. Furthermore, there might be educators and researchers out there who do not publish their investigations of study behaviors. Hence, this systematic literature review is limited to what peer reviewers have accepted, not what practitioners attempt to research.

The authors attempted to ensure an unbiased review process by developing a research protocol in advance with predefined research questions. The search string was developed using the research questions and considering a possible lack of standardization in keywords, as they can be disciplineand language-specific. Furthermore, we performed a search in relevant conferences and journal databases for the computing education discipline. In the data extraction and analysis phase, steps were taken to ensure that at least two authors independently examined the data. Based on the finding that theoretical definitions were lacking, we reflected on the implications of our quality criteria. The use of theory was not required for inclusion, which is not uncommon for literature reviews of this sort. Although the quality of the included research papers can be questioned, we do not believe that this possibility substantially diminishes the contributions of the article. Finally, the selected methodology is an in-depth investigation of a relatively narrow area, using specific and pointed research questions that entail certain limitations [10].

\section{CONCLUSION}

This review of study behaviors in computing education research aimed to investigate how the computing education research community has approached computing students' study behavior. In total, we analyzed 107 peer-reviewed articles from 1994 to 2019. We explored how study behaviors are defined and included in the research as well as the role of the educational context within the computing education field. The results indicate that what computing students do both in and outside the classroom when learning computing topics is of increasing interest to researchers and educators. We also found that that the terminology used to define study behaviors is challenging to navigate. Many different theories and data analysis approaches are in use, providing an excellent foundation to further strengthen the relationship between computing education and higher education disciplines [3]. However, there currently is a need to create common ground between higher education theories and definitions and computing education research. Simultaneously, educational context plays an under-communicated role in existing research, and context needs to be included in future works in a systematic way. The nature of the computing education discipline can facilitate great progress in gaining and utilizing knowledge about how students study. Nevertheless, when researching study behavior, the field of computing education can benefit from not "reinventing the wheel" for every new experiment and dataset, and the taxonomy of study behaviors in computing education presented in this article can provide a good starting point. We intend for this article to serve as a resource for the computing education research community to help practitioners find relevant work on study behaviors and to help researchers make clear contributions to the literature. 
APPENDIX

A COMPLETE LIST OF INCLUDED PAPERS

Table 11. List of Selected Papers in Alphabetical Order by Author

\begin{tabular}{|c|c|c|c|}
\hline Title & Year & Author(s) & Paper ID \\
\hline $\begin{array}{l}\text { A Study of Pair Programming Enjoyment } \\
\text { and Attendance using Study Motivation } \\
\text { and Strategy Metrics. }\end{array}$ & 2018 & Aarne et al. [1] & 1 \\
\hline $\begin{array}{l}\text { The effects of extra credit opportunities on } \\
\text { student procrastination. }\end{array}$ & 2013 & Allevato and Edwards [2] & 2 \\
\hline $\begin{array}{l}\text { Gender Differences in Students' Behaviors } \\
\text { in CS Classes throughout the CS Major }\end{array}$ & 2017 & Alvarado et al. [4] & 3 \\
\hline $\begin{array}{l}\text { Assessment of self-regulated attitudes and } \\
\text { behaviors of introductory programming } \\
\text { students }\end{array}$ & 2012 & Ambrosio et al. [5] & 4 \\
\hline $\begin{array}{l}\text { Altering Study Habits with Email } \\
\text { Reminders. }\end{array}$ & 2013 & $\mathrm{Au}$ et al. [6] & 5 \\
\hline $\begin{array}{l}\text { Prior Knowledge Dwarfs Hard Work in } \\
\text { Achieving Academic Performance }\end{array}$ & 2017 & Au et al. [7] & 6 \\
\hline $\begin{array}{l}\text { Harmful Study Habits in Online Learning } \\
\text { Environments with Automatic Assessment }\end{array}$ & 2015 & Auvinen [8] & 7 \\
\hline $\begin{array}{l}\text { When Life and Learning Do Not Fit: } \\
\text { Challenges of Workload and } \\
\text { Communication }\end{array}$ & 2012 & Benda et al. [11] & 8 \\
\hline $\begin{array}{l}\text { Promoting Students' Social Interactions } \\
\text { Results in an Improvement }\end{array}$ & 2018 & $\begin{array}{l}\text { Cabo and Satyanarayana } \\
{[19]}\end{array}$ & 9 \\
\hline $\begin{array}{l}\text { Retaking object-oriented programming } \\
\text { quizzes for study habit insights and } \\
\text { improvements }\end{array}$ & 2019 & $\begin{array}{l}\text { Carpenter and McCusker } \\
{[20]}\end{array}$ & 10 \\
\hline $\begin{array}{l}\text { Using learning style data in an } \\
\text { introductory computer science course }\end{array}$ & 1999 & $\begin{array}{c}\text { Chamillard and Karolick } \\
\text { [22] }\end{array}$ & 11 \\
\hline Learning styles across the curriculum & 2005 & Chamillard and Sward [23] & 12 \\
\hline $\begin{array}{l}\text { Study habits of CS1 students: what do they } \\
\text { do outside the classroom? }\end{array}$ & 2010 & Chinn et al. [24] & 13 \\
\hline $\begin{array}{l}\text { Finding traces of self-regulated learning in } \\
\text { activity streams. }\end{array}$ & 2018 & Cicchinelli et al. [25] & 14 \\
\hline $\begin{array}{l}\text { Facilitating Course Assessment with a } \\
\text { Competitive Programming Platform }\end{array}$ & 2019 & Coore and Fokum [27] & 15 \\
\hline $\begin{array}{l}\text { Introducing and Evaluating Exam } \\
\text { Wrappers in CS2 }\end{array}$ & 2016 & Craig et al. [28] & 16 \\
\hline $\begin{array}{l}\text { Predicting Success in University First Year } \\
\text { Computing Science Courses: The Role of } \\
\text { Student Participation in Reflective } \\
\text { Learning Activities and in I-clicker } \\
\text { Activities }\end{array}$ & 2015 & Cukierman [31] & 17 \\
\hline
\end{tabular}


Table 11. Continued

\begin{tabular}{|c|c|c|c|}
\hline Title & Year & Author(s) & Paper ID \\
\hline $\begin{array}{l}\text { The Academic Enhancement Program: } \\
\text { Assessing Programs Designed to Support } \\
\text { Student Success }\end{array}$ & 2019 & Cukierman et al. [32] & 18 \\
\hline $\begin{array}{l}\text { Teaching and assessing programming } \\
\text { strategies explicitly }\end{array}$ & 2009 & de Raadt et al. [33] & 19 \\
\hline $\begin{array}{l}\text { Predictors of academic achievement of } \\
\text { student ICT teachers with different } \\
\text { learning styles }\end{array}$ & 2009 & Deryakulu et al. [34] & 20 \\
\hline $\begin{array}{l}\text { Comparing effective and ineffective } \\
\text { behaviors of student programmers }\end{array}$ & 2009 & Edwards et al. [41] & 21 \\
\hline $\begin{array}{l}\text { Examining Classroom Interventions to } \\
\text { Reduce Procrastination }\end{array}$ & 2015 & Edwards et al. [40] & 22 \\
\hline $\begin{array}{l}\text { The academic enhancement program in } \\
\text { introductory CS: A workshop framework } \\
\text { description and evaluation }\end{array}$ & 2011 & Egan et al. [42] & 23 \\
\hline $\begin{array}{l}\text { Can Interaction Patterns with } \\
\text { Supplemental Study Tools Predict } \\
\text { Outcomes in CS1? }\end{array}$ & 2016 & Estey and Coady [45] & 24 \\
\hline $\begin{array}{l}\text { Study Habits, Exam Performance, and } \\
\text { Confidence: How Do Workflow Practices } \\
\text { and Self-Efficacy Ratings Align? }\end{array}$ & 2017 & Estey and Coady [46] & 25 \\
\hline $\begin{array}{l}\text { Automatically Classifying Students in } \\
\text { Need of Support by Detecting Changes in } \\
\text { Programming Behaviour }\end{array}$ & 2017 & Estey et al. [47] & 26 \\
\hline $\begin{array}{l}\text { From Study Tactics to Learning Strategies: } \\
\text { An Analytical Method for Extracting } \\
\text { Interpretable Representations }\end{array}$ & 2019 & Fincham et al. [48] & 27 \\
\hline $\begin{array}{l}\text { Improving Study Methods of Computer } \\
\text { Engineering Undergraduates in Singapore }\end{array}$ & 1996 & Foo and $\mathrm{Ng}$ [49] & 28 \\
\hline $\begin{array}{l}\text { Exploring students learning behavior with } \\
\text { an interactive etextbook in computer } \\
\text { science courses }\end{array}$ & 2014 & Fouh et al. [51] & 29 \\
\hline $\begin{array}{l}\text { The professor on your PC: a virtual CS1 } \\
\text { course }\end{array}$ & 2009 & Gal-Ezer et al. [54] & 30 \\
\hline $\begin{array}{l}\text { Learning and the Reflective Journal in } \\
\text { Computer Science }\end{array}$ & 2002 & George [56] & 31 \\
\hline $\begin{array}{l}\text { Student Behaviour in Unsupervised Online } \\
\text { Quizzes: A Closer Look }\end{array}$ & 2018 & Gholami and Zhang [58] & 32 \\
\hline $\begin{array}{l}\text { How Widely Can Prediction Models Be } \\
\text { Generalized? Performance Prediction in } \\
\text { Blended Courses }\end{array}$ & 2019 & Gitinabard et al. [59] & 33 \\
\hline $\begin{array}{l}\text { A study on students' behaviours and } \\
\text { attitudes towards learning to program }\end{array}$ & 2012 & Gomes et al. [61] & 34 \\
\hline
\end{tabular}


Table 11. Continued

\begin{tabular}{|c|c|c|c|}
\hline Title & Year & Author(s) & Paper ID \\
\hline $\begin{array}{l}\text { The learning context: Influence on learning } \\
\text { to program }\end{array}$ & 2009 & Govender [62] & 36 \\
\hline $\begin{array}{l}\text { Insights on supporting learning during } \\
\text { computing science and engineering } \\
\text { students' transition to university: A } \\
\text { design-oriented, mixed methods } \\
\text { exploration of instructor and student } \\
\text { perspectives }\end{array}$ & 2017 & Guloy et al. [63] & 37 \\
\hline $\begin{array}{l}\text { Psychology assisted prediction of academic } \\
\text { performance using machine learning }\end{array}$ & 2016 & Halde et al. [65] & 38 \\
\hline $\begin{array}{l}\text { Supporting quality teaching using } \\
\text { educational data mining based on } \\
\text { OpenEdX platform }\end{array}$ & 2017 & Han et al. [66] & 40 \\
\hline $\begin{array}{l}\text { Improving first-year success and retention } \\
\text { through interest-based CS0 courses }\end{array}$ & 2012 & Haungs et al. [68] & 41 \\
\hline $\begin{array}{l}\text { Metacognitive calibration when learning to } \\
\text { program }\end{array}$ & 2017 & Hauswirth and Adamoli [69] & 42 \\
\hline $\begin{array}{l}\text { Improving Study Skills by Combining a } \\
\text { Study Skill Module and Repeated } \\
\text { Reflection Seminars }\end{array}$ & 2019 & Hedin and Kann [70] & 43 \\
\hline $\begin{array}{l}\text { On the Bimodality in an Introductory } \\
\text { Programming Course: An Analysis of } \\
\text { Student Performance Factors }\end{array}$ & 2015 & Höök and Eckerdal [76] & 45 \\
\hline $\begin{array}{l}\text { Stereotype Modeling for Problem-Solving } \\
\text { Performance Predictions in MOOCs and } \\
\text { Traditional Courses }\end{array}$ & 2017 & Hosseini et al. [73] & 46 \\
\hline $\begin{array}{l}\text { ASSISTing CS1 students to learn: learning } \\
\text { approaches and object-oriented } \\
\text { programming }\end{array}$ & 2006 & Hughes and Peiris [74] & 47 \\
\hline $\begin{array}{l}\text { How Can Learning Analytics Improve a } \\
\text { Course? }\end{array}$ & 2017 & Hui and Farvolden [75] & 48 \\
\hline Study strategies of online learners & 2011 & Iscioglu [77] & 49 \\
\hline $\begin{array}{l}\text { Teaching programming by emphasizing } \\
\text { self-direction: How did students react to } \\
\text { the active role required of them? }\end{array}$ & 2013 & $\begin{array}{l}\text { Isomöttönen and Tirronen } \\
{[78]}\end{array}$ & 50 \\
\hline $\begin{array}{l}\text { Flipping and Blending-An Action } \\
\text { Research Project on Improving a } \\
\text { Functional Programming Course }\end{array}$ & 2016 & $\begin{array}{l}\text { Isomöttönen and Tirronen } \\
{[79]}\end{array}$ & 51 \\
\hline $\begin{array}{l}\text { Issues with a course that emphasizes } \\
\text { self-direction }\end{array}$ & 2013 & Isomöttönen et al. [80] & 52 \\
\hline $\begin{array}{l}\text { Effects of a Program Integrating Course for } \\
\text { Students of Computer Science and } \\
\text { Engineering }\end{array}$ & 2016 & Kann and Högfeldt [81] & 53 \\
\hline
\end{tabular}


Table 11. Continued

\begin{tabular}{|c|c|c|c|}
\hline Title & Year & Author(s) & Paper ID \\
\hline CS minors in a CS1 course & 2008 & Kinnunen and Malmi [84] & 54 \\
\hline $\begin{array}{l}\text { Through the eyes of instructors: a } \\
\text { phenomenographic investigation of } \\
\text { student success. }\end{array}$ & 2007 & Kinnunen et al. [85] & 55 \\
\hline $\begin{array}{l}\text { Penetrating the black box of time-on-task } \\
\text { estimation }\end{array}$ & 2015 & Kovanović et al. [89] & 56 \\
\hline $\begin{array}{l}\text { Examining communities of inquiry in } \\
\text { Massive Open Online Courses: The role of } \\
\text { study strategies }\end{array}$ & 2019 & Kovanović et al. [90] & 57 \\
\hline $\begin{array}{l}\text { An expert system for the prediction of } \\
\text { student performance in an initial computer } \\
\text { science course }\end{array}$ & 2017 & Kuehn et al. [91] & 58 \\
\hline $\begin{array}{l}\text { The Effectiveness of Video Quizzes in a } \\
\text { Flipped Class }\end{array}$ & 2015 & Lacher and Lewis [93] & 59 \\
\hline Pauses and spacing in learning to program & 2016 & Leppänen et al. [94] & 60 \\
\hline $\begin{array}{l}\text { Behaviors of Higher and Lower Performing } \\
\text { Students in CS1 }\end{array}$ & 2019 & Liao et al. [95] & 62 \\
\hline $\begin{array}{l}\text { Exploring the Network Dynamics in a } \\
\text { Flipped Classroom }\end{array}$ & 2018 & Lin and $\mathrm{Wu}[96]$ & 63 \\
\hline $\begin{array}{l}\text { Cross-cultural education: learning } \\
\text { methodology and behaviour analysis for } \\
\text { Asian students in IT field of Australian } \\
\text { universities }\end{array}$ & 2010 & Lu et al. [99] & 64 \\
\hline $\begin{array}{l}\text { Problem-based learning with database } \\
\text { systems }\end{array}$ & 1994 & Ma [101] & 65 \\
\hline $\begin{array}{l}\text { Video-based instruction for introductory } \\
\text { computer programming }\end{array}$ & 2014 & Manley and Urness [103] & 66 \\
\hline $\begin{array}{l}\text { The Effects of Procrastination } \\
\text { Interventions on Programming Project } \\
\text { Success }\end{array}$ & 2015 & Martin et al. [105] & 67 \\
\hline $\begin{array}{l}\text { Game elements in a software engineering } \\
\text { study group: A case study }\end{array}$ & 2017 & $\begin{array}{l}\text { Matsubara and da Silva } \\
{[108]}\end{array}$ & 35 \\
\hline $\begin{array}{l}\text { When Practice Doesn't Make Perfect: } \\
\text { Effects of Task Goals on Learning } \\
\text { Computing Concepts }\end{array}$ & 2011 & Miller and Settle [111] & 71 \\
\hline $\begin{array}{l}\text { Making connections: First year transition } \\
\text { for computer science and software } \\
\text { engineering students }\end{array}$ & 2005 & Moffat et al. [112] & 72 \\
\hline Modeling Students Self-studies Behaviors & 2015 & Mota et al. [113] & 73 \\
\hline $\begin{array}{l}\text { Social Help-seeking Strategies in a } \\
\text { Programming MOOC }\end{array}$ & 2018 & Nelimarkka and Hellas [114] & 74 \\
\hline
\end{tabular}


Table 11. Continued

\begin{tabular}{|c|c|c|c|}
\hline Title & Year & Author(s) & Paper ID \\
\hline $\begin{array}{l}\text { Undergraduate students in a computer } \\
\text { engineering course: a perspective of their } \\
\text { learning approaches and motivation factors }\end{array}$ & 1997 & $\mathrm{Ng}$ and $\mathrm{Ng}$ [117] & 75 \\
\hline $\begin{array}{l}\text { Examining the mediating role of learning } \\
\text { engagement, learning process and learning } \\
\text { experience on the learning outcomes } \\
\text { through localized real case studies }\end{array}$ & 2014 & Nkhoma et al. [118] & 76 \\
\hline $\begin{array}{l}\text { Investigating Students' Achievements in } \\
\text { Computing Science Using Human Metric }\end{array}$ & 2014 & Okike [120] & 77 \\
\hline $\begin{array}{l}\text { Illustrating performance indicators and } \\
\text { course characteristics to support students' } \\
\text { self-regulated learning in CS1 }\end{array}$ & 2015 & Ott et al. [121] & 78 \\
\hline $\begin{array}{l}\text { Does the introduction of an overall study } \\
\text { strategy empower students to use } \\
\text { appropriate study strategies? }\end{array}$ & 2017 & Oysaed et al. [122] & 79 \\
\hline $\begin{array}{l}\text { What's the Problem? Teachers' Experience } \\
\text { of Student Learning Successes and Failures }\end{array}$ & 2007 & Pears et al. [124] & 80 \\
\hline Revisiting why students drop CS1 & 2016 & Petersen et al. [125] & 81 \\
\hline $\begin{array}{l}\text { Approaches to studying in first-year } \\
\text { engineering: comparison between } \\
\text { inventory scores and students' descriptions } \\
\text { of their approaches through interviews }\end{array}$ & 2018 & Pettersson et al. [126] & 82 \\
\hline $\begin{array}{l}\text { Anchoring interactive points of interest on } \\
\text { web-based instructional video: effects on } \\
\text { students' interaction behavior and } \\
\text { perceived experience }\end{array}$ & 2019 & Pimentel et al. [127] & 83 \\
\hline $\begin{array}{l}\text { SAT Does Not Spell Success: How } \\
\text { Non-Cognitive Factors Can Explain } \\
\text { Variance in the GPA of Undergraduate } \\
\text { Engineering and Computer Science } \\
\text { Students }\end{array}$ & 2019 & Scheidt et al. [136] & 87 \\
\hline $\begin{array}{l}\text { Evaluating a Linked-courses Learning } \\
\text { Community for Development Majors }\end{array}$ & 2015 & Settle et al. [138] & 89 \\
\hline $\begin{array}{l}\text { Ludwig: an online programming tutoring } \\
\text { and assessment system }\end{array}$ & 2005 & Shaffer [139] & 90 \\
\hline $\begin{array}{l}\text { Study Habits of CS } 1 \text { Students: What Do } \\
\text { They Say They Do? }\end{array}$ & 2013 & Sheard et al. [140] & 91 \\
\hline $\begin{array}{l}\text { On multi-device use: Using technological } \\
\text { modality profiles to explain differences in } \\
\text { students' learning }\end{array}$ & 2019 & Sher et al. [141] & 92 \\
\hline $\begin{array}{l}\text { Predicting Student Performance Based on } \\
\text { Online Study Habits: A Study of Blended } \\
\text { Courses. }\end{array}$ & 2018 & Sheshadri et al. [142] & 93 \\
\hline
\end{tabular}


Table 11. Continued

\begin{tabular}{|c|c|c|c|}
\hline Title & Year & Author(s) & Paper ID \\
\hline An Exploration of Grit in a CS1 Context & 2018 & $\begin{array}{l}\text { Sigurdson and Petersen } \\
\text { [143] }\end{array}$ & 94 \\
\hline $\begin{array}{l}\text { Predictors of success in a first } \\
\text { programming course }\end{array}$ & 2006 & Simon et al. [144] & 95 \\
\hline $\begin{array}{l}\text { Analyzing self-reflection by Computer } \\
\text { Science students to identify bad study } \\
\text { habits: Self-reflection performed by } \\
\text { students of programming courses on the } \\
\text { study habits and skills acquired through } \\
\text { b-learning supported by an automatic } \\
\text { judge }\end{array}$ & 2010 & Sustelo and Guerreiro [146] & 96 \\
\hline $\begin{array}{l}\text { Gender neutrality improved completion } \\
\text { rate for all }\end{array}$ & 2016 & Svedin and Bälter [147] & 97 \\
\hline $\begin{array}{l}\text { Repertory grid: investigating personal } \\
\text { constructs of novice programmers }\end{array}$ & 2011 & Thota [149] & 98 \\
\hline $\begin{array}{l}\text { The influence of Web-supported } \\
\text { independent activities and small group } \\
\text { work on students' epistemological beliefs }\end{array}$ & 2004 & Tolhurst [151] & 99 \\
\hline $\begin{array}{l}\text { How novices tackle their first lines of code } \\
\text { in an IDE: Analysis of programming } \\
\text { session traces }\end{array}$ & 2014 & Vihavainen et al. [154] & 101 \\
\hline $\begin{array}{l}\text { Approaches of Learning and } \\
\text { Computational Thinking in Students that } \\
\text { get into the Computer Sciences Career }\end{array}$ & 2018 & Villalba-Condori et al. [155] & 102 \\
\hline $\begin{array}{l}\text { The use of lecture videos, eBooks, and } \\
\text { clickers in computer courses }\end{array}$ & 2014 & Vinaja [156] & 103 \\
\hline $\begin{array}{l}\text { Pedagogical Intervention Practices: } \\
\text { Improving Learning Engagement Based on } \\
\text { Early Prediction }\end{array}$ & 2019 & Wan et al. [157] & 104 \\
\hline $\begin{array}{l}\text { SmartGPA: how smartphones can assess } \\
\text { and predict academic performance of } \\
\text { college students }\end{array}$ & 2015 & Wang et al. [158] & 105 \\
\hline $\begin{array}{l}\text { The combined effect of self-efficacy and } \\
\text { academic integration on higher education } \\
\text { students studying IT majors in Taiwan }\end{array}$ & 2010 & Weng et al. [159] & 107 \\
\hline Teaching OO concepts-A new approach & 2004 & Westin and Nordstrom [160] & 108 \\
\hline $\begin{array}{l}\text { Implementation of alternative pacing in an } \\
\text { introductory programming sequence }\end{array}$ & 2003 & Whittington et al. [161] & 109 \\
\hline $\begin{array}{l}\text { Using online self-assessment in } \\
\text { introductory programming classes }\end{array}$ & 2006 & Williams et al. [162] & 110 \\
\hline $\begin{array}{l}\text { On study habits on an introductory course } \\
\text { on programming }\end{array}$ & 2015 & Willman et al. [164] & 111 \\
\hline
\end{tabular}


Table 11. Continued

\begin{tabular}{|c|c|c|c|}
\hline Title & Year & Author(s) & Paper ID \\
\hline $\begin{array}{l}\text { A Spaced, Interleaved Retrieval Practice } \\
\text { Tool that is Motivating and Effective }\end{array}$ & 2019 & YeckehZaare et al. [166] & 112 \\
\hline $\begin{array}{l}\text { Effects of YouTube videos as pre-lecture } \\
\text { preparation }\end{array}$ & 2019 & Yim et al. [167] & 113 \\
\hline $\begin{array}{l}\text { Investigation of the Relationship between } \\
\text { Learning Process and Learning Outcomes } \\
\text { in E-learning Environments }\end{array}$ & 2015 & $\begin{array}{l}\text { Yurdugul and Menzi Cetin } \\
\qquad[168]\end{array}$ & 114 \\
\hline $\begin{array}{l}\text { Finding competence characteristics among } \\
\text { first semester students in computer science }\end{array}$ & 2015 & Zehetmeier et al. [169] & 115 \\
\hline $\begin{array}{l}\text { DataLab: Introducing Software } \\
\text { Engineering Thinking into Data Science } \\
\text { Education at Scale }\end{array}$ & 2017 & Zhang et al. [170] & 116 \\
\hline $\begin{array}{l}\text { The Effects of ICT Use on Chinese College } \\
\text { Students' Study Behavior in B-learning } \\
\text { Evaluating B-learning Effectiveness via } \\
\text { Causal Model }\end{array}$ & 2019 & Zhao et al. [171] & 117 \\
\hline $\begin{array}{l}\text { Impact of Student Achievement Goals on } \\
\text { CS1 Outcomes }\end{array}$ & 2016 & Zingaro and Porter [173] & 118 \\
\hline $\begin{array}{l}\text { Achievement Goals in CS1: Replication and } \\
\text { Extension }\end{array}$ & 2018 & Zingaro et al. [172] & 119 \\
\hline
\end{tabular}

Paper ID refers to the key in the results from the coding process at this link [removed for anonymous review but will be made available in an online format upon publication].

\section{ACKNOWLEDGMENTS}

We would like to especially acknowledge Tore Sletten Langeland for valuable input on the taxonomy. In addition, we are extremely grateful to the associate editor and the reviewers for their constructive comments and useful insights, which significantly improved the article.

\section{REFERENCES}

[1] Onni Aarne, Petrus Peltola, Juho Leinonen, and Arto Hellas. 2018. A study of pair programming enjoyment and attendance using study motivation and strategy metrics. In Proceedings of the 49th ACM Technical Symposium on Computer Science Education (SIGCSE'18). Association for Computing Machinery, New York, NY, 759-764. DOI : https: //doi.org/10.1145/3159450.3159493

[2] A. Allevato and S. H. Edwards. 2013. The effects of extra credit opportunities on student procrastination. In Proceedings of the Frontiers in Education Conference (FIE'13). 1831-1836. DOI : https://doi.org/10.1109/FIE.2013.6685154

[3] Vicki L. Almstrum, Orit Hazzan, Mark Guzdial, and Marian Petre. 2005. Challenges to computer science education research. In Proceedings of the 36th SIGCSE Technical Symposium on Computer Science Education (SIGCSE'05). ACM, New York, NY, 191-192. DOI : https://doi.org/10.1145/1047344.1047415

[4] Christine Alvarado, Yingjun Cao, and Mia Minnes. 2017. Gender differences in students' behaviors in CS classes throughout the CS major. In Proceedings of the ACM SIGCSE Technical Symposium on Computer Science Education (SIGCSE'17). Association for Computing Machinery, New York, NY, 27-32. DOI : https://doi.org/10.1145/3017680. 3017771

[5] A. P. Ambrosio, L. Almeida, A. Franco, S. Martins, and F. Georges. 2012. Assessment of self-regulated attitudes and behaviors of introductory programming students. DOI : https://doi.org/10.1109/FIE.2012.6462314

[6] Oliver Au, Raymond So, and Hiu-Wing Go. 2013. Altering study habits with email reminders (Lecture Notes in Computer Science (including subseries Lecture Notes in Artificial Intelligence and Lecture Notes in Bioinformatics)), Vol. 8038 LNCS, 190-198. DOI : https://doi.org/10.1007/978-3-642-39750-9_18 
[7] Oliver Au, Raymond So, and Lap Kei Lee. 2017. Prior knowledge dwarfs hard work in achieving academic performance. In Blended Learning. New Challenges and Innovative Practices (Lecture Notes in Computer Science), Simon K. S. Cheung, Lam-for Kwok, Will W. K. Ma, Lap-Kei Lee, and Harrison Yang (Eds.). Springer International Publishing, Cham, 139-147. DOI : https://doi.org/10.1007/978-3-319-59360-9_13

[8] T. Auvinen. 2015. Harmful study habits in online learning environments with automatic assessment. In Proceedings of the International Conference on Learning and Teaching in Computing and Engineering. 50-57. DOI : https://doi.org/ 10.1109/LaTiCE.2015.31

[9] Albert Bandura. 1978. The self system in reciprocal determinism. Amer. Psychol. 33, 4 (1978), 344-358. DOI : https: //doi.org/10.1037/0003-066X.33.4.344

[10] Margaret Bearman, Calvin D. Smith, Angela Carbone, Susan Slade, Chi Baik, Marnie Hughes-Warrington, and David L. Neumann. 2012. Systematic review methodology in higher education. High. Educ. Res. Devel. 31, 5 (Oct. 2012), 625-640. DOI : https://doi.org/10.1080/07294360.2012.702735

[11] Klara Benda, Amy Bruckman, and Mark Guzdial. 2012. When life and learning do not fit: Challenges of workload and communication in introductory computer science online. ACM Trans. Comput. Educ. 12, 4 (Nov. 2012). DOI : https: //doi.org/10.1145/2382564.2382567

[12] Anders Berglund and Mattias Wiggberg. 2006. Students learn CS in different ways: Insights from an empirical study. In Proceedings of the 11th Annual SIGCSE Conference on Innovation and Technology in Computer Science Education (ITICSE'06). Association for Computing Machinery, New York, NY, 265-269. DOI : https://doi.org/10.1145/1140124. 1140195

[13] Naomi Berman. 2020. A critical examination of informal learning spaces. High. Educ. Res. Devel. 39, 1 (Jan. 2020), 127-140. DOI : https://doi.org/10.1080/07294360.2019.1670147

[14] John Biggs. 1979. Individual differences in study processes and the quality of learning outcomes. High. Educ. 8, 4 (1979), 381-394.

[15] John Biggs. 2012. What the student does: Teaching for enhanced learning. High. Educ. Res. Devel. 31, 1 (Feb. 2012), 39-55. DOI : https://doi.org/10.1080/07294360.2012.642839

[16] John Biggs, David Kember, and Doris Y. P. Leung. 2001. The revised two-factor study process questionnaire: R-SPQ2F. Brit. F. Educ. Psychol. 71, 1 (2001), 133-149. DOI : https://doi.org/10.1348/000709901158433

[17] John B. Biggs. 1989. Approaches to the enhancement of tertiary teaching. High. Educ. Res. Devel. 8, 1 (Jan. 1989$), 7-25$. DOI : https://doi.org/10.1080/0729436890080102

[18] Jürgen Börstler and Thomas B. Hilburn. 2015. Team projects in computing education. ACM Trans. Comput. Educ. 15, 4 (Dec. 2015), 1-5. DOI : https://doi.org/10.1145/2808079

[19] Candido Cabo and Ashwin Satyanarayana. 2018. Promoting students' social interactions results in an improvement in performance, class attendance and retention in first year computing courses. In Proceedings of the Frontiers in Education Conference.

[20] A. Carpenter and J. R. McCusker. 2019. Retaking object-oriented programming quizzes for study habit insights and improvements. In 2019 ASEE Annual Conference \& Exposition.

[21] Leen Catrysse, David Gijbels, and Vincent Donche. 2019. A systematic review on the conceptualization and operationalization of students' levels of processing in functional magnetic resonance imaging studies. Mind, Brain Educ. 13, 3 (2019), 198-210. DOI : https://doi.org/10.1111/mbe.12199

[22] A. T. Chamillard and D. Karolick. 1999. Using learning style data in an introductory computer science course. In Proceedings of the Thirtieth SIGCSE Technical Symposium on Computer Science Education. 291-295.

[23] A. T. Chamillard and Ricky E. Sward. 2005. Learning styles across the curriculum. In Proceedings of the 10th Annual SIGCSE Conference on Innovation and Technology in Computer Science Education (ITiCSE'05). Association for Computing Machinery, New York, NY, 241-245. DOI : https://doi.org/10.1145/1067445.1067512

[24] Donald Chinn, Judy Sheard, Angela Carbone, and Mikko-Jussi Laakso. 2010. Study habits of CS1 Students: What do they do outside the classroom? In Proceedings of the 12th Australasian Conference on Computing Education (ACE'10). Australian Computer Society, Inc., 53-62.

[25] Analía Cicchinelli, Eduardo Veas, Abelardo Pardo, Viktoria Pammer-Schindler, Angela Fessl, Carla Barreiros, and Stefanie Lindstädt. 2018. Finding traces of self-regulated learning in activity streams. In Proceedings of the 8th international conference on learning analytics and knowledge (LAK'18). Association for Computing Machinery, New York, NY, 191-200. DOI : https://doi.org/10.1145/3170358.3170381

[26] Frank Coffield. 2004. Should We Be Using Learning Styles? What Research Has to Say in Practice. Technical Report. Learning and Skills Research Centre, London.

[27] Daniel Coore and Daniel Fokum. 2019. Facilitating course assessment with a competitive programming platform. In Proceedings of the 50th ACM Technical Symposium on Computer Science Education (SIGCSE'19). Association for Computing Machinery, New York, NY, 449-455. DOI : https://doi.org/10.1145/3287324.3287511 
[28] Michelle Craig, Diane Horton, Daniel Zingaro, and Danny Heap. 2016. Introducing and evaluating exam wrappers in CS2. In Proceedings of the 47th ACM Technical Symposium on Computer Science Education (SIGCSE'16). Association for Computing Machinery, New York, NY, 285-290. DOI : https://doi.org/10.1145/2839509.2844561

[29] Fergus I. M. Craik and Robert S. Lockhart. 1972. Levels of processing: A framework for memory research. J. Verb. Learn. and Verb. Behav. 11, 6 (Dec. 1972), 671-684. D0I : https://doi.org/10.1016/S0022-5371(72)80001-X

[30] Marcus Credé and Nathan R. Kuncel. 2008. Study habits, skills, and attitudes: The third pillar supporting collegiate academic performance. Perspect. Psychol. Sci. 3, 6 (Nov. 2008), 425-453. DOI : https://doi.org/10.1111/j.1745-6924.2008 00089.x

[31] Diana Cukierman. 2015. Predicting success in university first year computing science courses: The role of student participation in reflective learning activities and in i-Clicker activities. In Proceedings of the ACM Conference on Innovation and Technology in Computer Science Education (ITiCSE'15). Association for Computing Machinery, New York, NY, 248-253. DOI : https://doi.org/10.1145/2729094.2742623

[32] Diana R. Cukierman, Donna McGee Thompson, and Wayne Sun. 2019. The academic enhancement program: Assessing programs designed to support student success. In Proceedings of the 50th ACM Technical Symposium on Computer Science Education (SIGCSE'19). Association for Computing Machinery, New York, NY, 686-692. DOI : https: //doi.org/10.1145/3287324.3287422

[33] Michael de Raadt, Richard Watson, and Mark Toleman. 2009. Teaching and assessing programming strategies explicitly. New Zealand 95 (2009), 10.

[34] D. Deryakulu, S. Büyüköztürk, and H. Özçinar. 2009. Predictors of academic achievement of student ICT teachers with different learning styles. World Acad. Sci., Eng. Technol. 58 (2009), 703-709.

[35] Cambridge Dictionary. 2021. taxonomy. Retrived 18 Feb, 2021 from https://cambridge.dictinary.com/taxonomy.

[36] Daniel L. Dinsmore. 2017. Toward a dynamic, multidimensional research framework for strategic processing. Educ. Psychol. Rev. 29, 2 (June 2017), 235-268. DOI : https://doi.org/10.1007/s10648-017-9407-5

[37] Daniel L. Dinsmore, Patricia A. Alexander, and Sandra M. Loughlin. 2008. Focusing the conceptual lens on metacognition, self-regulation, and self-regulated learning. Educ. Psychol. Rev. 20, 4 (Dec. 2008), 391-409. DOI : https://doi.org/ 10.1007/s10648-008-9083-6

[38] Angela Lee Duckworth and Patrick D. Quinn. 2009. Development and validation of the short grit scale (Grit-S). F. Personal. Assess. 91, 2 (Feb. 2009), 166-174. DOI : https://doi.org/10.1080/00223890802634290

[39] Tore Dybå and Torgeir Dingsøyr. 2008. Empirical studies of agile software development: A systematic review. Inf. Softw. Technol. 50, 9 (Aug. 2008), 833-859. DOI : https://doi.org/10.1016/j.infsof.2008.01.006

[40] Stephen H. Edwards, Joshua Martin, and Clfford A. Shaffer. 2015. Examining classroom interventions to reduce procrastination. In Proceedings of the ACM Conference on Innovation and Technology in Computer Science Education (ITiCSE'15). Association for Computing Machinery, New York, NY, 254-259. DOI : https://doi.org/10.1145/2729094. 2742632

[41] Stephen H. Edwards, Jason Snyder, Manuel A. Pérez-Quiñones, Anthony Allevato, Dongkwan Kim, and Betsy Tretola. 2009. Comparing effective and ineffective behaviors of student programmers. In Proceedings of the 5th International Workshop on Computing Education Research Workshop (ICER'09). ACM, New York, NY, 3-14. DOI : https://doi.org/10. $1145 / 1584322.1584325$

[42] Rylan Egan, Diana Cukierman, and Donna McGee Thompson. 2011. The academic enhancement program in introductory CS: A workshop framework description and evaluation. In Proceedings of the 16th Annual foint Conference on Innovation and Technology in Computer Science Education (ITiCSE'11). Association for Computing Machinery, New York, NY, 278-282. DOI : https://doi.org/10.1145/1999747.1999825

[43] Noel Entwistle and Paul Ramsden. 2015. Understanding Student Learning (Routledge Revivals). Routledge. DOI : https: //doi.org/10.4324/9781315718637

[44] N. J. Entwistle. 1991. Approaches to learning and perceptions of the learning environment: Introduction to the Special Issue. High. Educ. 22, 3 (1991), 201-4.

[45] Anthony Estey and Yvonne Coady. 2016. Can interaction patterns with supplemental study tools predict outcomes in CS1? In Proceedings of the ACM Conference on Innovation and Technology in Computer Science Education (ITiCSE'16). Association for Computing Machinery, New York, NY, 236-241. DOI : https://doi.org/10.1145/2899415.2899428

[46] Anthony Estey and Yvonne Coady. 2017. Study habits, exam performance, and confidence: How do workflow practices and self-efficacy ratings align? In Proceedings of the ACM Conference on Innovation and Technology in Computer Science Education (ITiCSE'17). Association for Computing Machinery, New York, NY, 158-163. DOI : https: //doi.org/10.1145/3059009.3059056

[47] Anthony Estey, Hieke Keuning, and Yvonne Coady. 2017. Automatically classifying students in need of support by detecting changes in programming behaviour. In Proceedings of the ACM SIGCSE Technical Symposium on Computer Science Education (SIGCSE'17). Association for Computing Machinery, New York, NY, 189-194. DOI : https://doi.org/ 10.1145/3017680.3017790 
[48] E. Fincham, D. Gašević, J. Jovanović, and A. Pardo. 2019. From study tactics to learning strategies: An analytical method for extracting interpretable representations. IEEE Trans. Learn. Technol. 12, 1 (2019), 59-72. DOI : https://doi. org/10.1109/TLT.2018.2823317

[49] S. Foo and G. S. Ng. 1996. Improving study methods of computer engineering undergraduates in Singapore. Qual. High. Educ. 2, 2 (1996), 131-142. DOI : https://doi.org/10.1080/1353832960020205

[50] The Joint Task Force for Computing Curricula. 2005. Computing Curricula 2005 - The Overview Report. Technical Report. ACM, AIS, IEEE.

[51] E. Fouh, D. A. Breakiron, S. Hamouda, M. F. Farghally, and C. A. Shaffer. 2014. Exploring students' learning behavior with an interactive etextbook in computer science courses. Comput. Hum. Behav. 41 (2014), 478-485. DOI: https: //doi.org/10.1016/j.chb.2014.09.061

[52] Stephen Frezza, Mats Daniels, Arnold Pears, Åsa Cajander, Viggo Kann, Amanpreet Kapoor, Roger McDermott, Anne-Kathrin Peters, Mihaela Sabin, and Charles Wallace. 2018. Modelling competencies for computing education beyond 2020: A research based approach to defining competencies in the computing disciplines. In Proceedings of the 23rd Annual ACM Conference on Innovation and Technology in Computer Science Education (ITiCSE'18). Association for Computing Machinery, New York, NY, 148-174. DOI : https://doi.org/10.1145/3293881.3295782

[53] Luke K. Fryer, Paul Ginns, Richard A. Walker, and Kaori Nakao. 2012. The adaptation and validation of the CEQ and the R-SPQ-2F to the Japanese tertiary environment. Brit. F. Educ. Psychol. 82, 4 (2012), 549-563. DOI : https://doi.org/ 10.1111/j.2044-8279.2011.02045.x

[54] Judith Gal-Ezer, Tamar Vilner, and Ela Zur. 2009. The professor on your PC: A virtual CS1 course. In Proceedings of the 14th Annual ACM SIGCSE Conference on Innovation and Technology in Computer Science Education (ITiCSE'09). Association for Computing Machinery, New York, NY, 191-195. DOI : https://doi.org/10.1145/1562877.1562938

[55] Dragan Gaševic, Jelena Jovanovic, Abelardo Pardo, and Shane Dawson. 2017. Detecting learning strategies with analytics: Links with self-reported measures and academic performance. F. Learn. Anal. 4, 2 (2017), 113-128.

[56] Susan E. George. 2002. Learning and the reflective journal in computer science. In Proceedings of the 25th Australasian Conference on Computer Science (ACSC'02). Australian Computer Society, Inc., AUS, 77-86.

[57] Maribeth Gettinger and Jill K. Seibert. 2002. Contributions of study skills to academic competence. Study Skills 31,3 (2002), 350-365.

[58] A. Gholami and L. Y. Zhang. 2018. Student behaviour in unsupervised online quizzes: A closer look. In Proceedings of the 23rd Western Canadian Conference on Computing Education. DOI : https://doi.org/10.1145/3209635.3209650

[59] N. Gitinabard, Y. Xu, S. Heckman, T. Barnes, and C. F. Lynch. 2019. How widely can prediction models be generalized? Performance prediction in blended courses. IEEE Trans. Learn. Technol. 12, 2 (2019), 184-197. DOI : https://doi.org/10. 1109/TLT.2019.2911832

[60] Seth Copen Goldstein, Hongyi Zhang, Majd Sakr, Haokang An, and Cameron Dashti. 2019. Understanding how work habits influence student performance. In Proceedings of the ACM Conference on Innovation and Technology in Computer Science Education (ITiCSE'19). ACM, New York, NY, 154-160. DOI : https://doi.org/10.1145/3304221.3319757

[61] Anabela Jesus Gomes, Alvaro Nuno Santos, and António José Mendes. 2012. A study on students' behaviours and attitudes towards learning to program. In Proceedings of the 17th ACM Annual Conference on Innovation and Technology in Computer Science Education (ITiCSE'12). ACM, New York, NY, 132-137. DOI : https://doi.org/10.1145/2325296.2325331

[62] Irene Govender. 2009. The learning context: Influence on learning to program. Comput. Educ. 53, 4 (Dec. 2009), 12181230. DOI : https://doi.org/\{10.1016/j.compedu.2009.06.005\}

[63] Sheryl Guloy, Farimah Salimi, Diana Cukierman, and Donna McGee Thompson. 2017. Insights on supporting learning during computing science and engineering students' transition to university: A design-oriented, mixed methods exploration of instructor and student perspectives. High. Educ. 73, 3, SI (Mar. 2017), 479-497. DOI: https: //doi.org/\{10.1007/s10734-016-0097-6\}

[64] Tamsin Haggis. 2003. Constructing images of ourselves? A critical investigation into "approaches to learning" research in higher education. Brit. Educ. Res. F. 29, 1 (2003), 89-104. DOI : https://doi.org/10.1080/0141192032000057401

[65] R. R. Halde, A. Deshpande, and A. Mahajan. 2016. Psychology assisted prediction of academic performance using machine learning. In Proceedings of the IEEE International Conference on Recent Trends in Electronics, Information and Communication Technology (RTEICT). 431-435. DOI : https://doi.org/10.1109/RTEICT.2016.7807857

[66] Wan Han, Ding Jun, Gao Xiaopeng, and Liu Kangxu. 2017. Supporting quality teaching using educational data mining based on OpenEDX platform. In Proceedings of the IEEE Frontiers in Education Conference (FIE'17). 1-7. DOI: https: //doi.org/10.1109/FIE.2017.8190730

[67] David Harel. 1980. On folk theorems. Commun. ACM 23, 7 (July 1980), 379-389. DOI : https://doi.org/10.1145/358886. 358892

[68] Michael Haungs, Christopher Clark, John Clements, and David Janzen. 2012. Improving first-year success and retention through interest-based CS0 courses. In Proceedings of the 43rd ACM Technical Symposium on Computer Science Education (SIGCSE'12). Association for Computing Machinery, New York, NY, 589-594. DOI : https://doi.org/10.1145/ 2157136.2157307 
[69] Matthias Hauswirth and Andrea Adamoli. 2017. Metacognitive calibration when learning to program. In Proceedings of the 17th Koli Calling International Conference on Computing Education Research (Koli Calling'17). Association for Computing Machinery, New York, NY, 50-59. DOI : https://doi.org/10.1145/3141880.3141904

[70] Bjorn Hedin and Viggo Kann. 2019. Improving study skills by combining a study skill module and repeated reflection seminars. Educ. Res. Int. (2019). DOI : https://doi.org/\{10.1155/2019/9739854\}

[71] Arto Hellas, Petri Ihantola, Andrew Petersen, Vangel V. Ajanovski, Mirela Gutica, Timo Hynninen, Antti Knutas, Juho Leinonen, Chris Messom, and Soohyun Nam Liao. 2018. Predicting academic performance: A systematic literature review. In Proceedings of the 23rd Annual ACM Conference on Innovation and Technology in Computer Science Education (ITiCSE'18). ACM, New York, NY, 175-199. DOI : https://doi.org/10.1145/3293881.3295783

[72] Barbara K. Hofer. 2000. Dimensionality and disciplinary differences in personal epistemology. Contemp. Educ. Psychol. 25, 4 (Oct. 2000), 378-405. DOI : https://doi.org/10.1006/ceps.1999.1026

[73] Roya Hosseini, Peter Brusilovsky, Michael Yudelson, and Arto Hellas. 2017. Stereotype modeling for problem-solving performance predictions in MOOCs and traditional courses. In Proceedings of the 25th Conference on User Modeling, Adaptation and Personalization (UMAP'17). Association for Computing Machinery, New York, NY, 76-84. DOI : https: //doi.org/10.1145/3079628.3079672

[74] Janet Hughes and D. Ramanee Peiris. 2006. ASSISTing CS1 students to learn: Learning approaches and objectoriented programming. In Proceedings of the 11th Annual SIGCSE Conference on Innovation and Technology in Computer Science Education (ITICSE'06). Association for Computing Machinery, New York, NY, 275-279. DOI : https: //doi.org/10.1145/1140124.1140197

[75] Bowen Hui and Shannon Farvolden. 2017. How can learning analytics improve a course? In Proceedings of the 22nd Western Canadian Conference on Computing Education (WCCCE'17). Association for Computing Machinery, New York, NY. DOI : https://doi.org/10.1145/3085585.3085586

[76] Lars Josef Höök and Anna Eckerdal. 2015. On the bimodality in an introductory programming course: An analysis of student performance factors. In Proceedings of the International Conference on Learning and Teaching in Computing and Engineering. 79-86. DOI : https://doi.org/10.1109/LaTiCE.2015.25

[77] Ersun Iscioglu. 2011. Study strategies of online learners. In Proceedings of the International Conference on Virtual Learning. 358-364.

[78] Ville Isomöttönen and Ville Tirronen. 2013. Teaching programming by emphasizing self-direction: How did students react to the active role required of them? ACM Trans. Comput. Educ. 13, 2 (July 2013). DOI : https://doi.org/10.1145/ 2483710.2483711

[79] Ville Isomöttönen and Ville Tirronen. 2016. Flipping and Blending-An action research project on improving a functional programming course. ACM Trans. Comput. Educ. 17, 1 (Sept. 2016). DOI : https://doi.org/10.1145/2934697

[80] Ville Isomöttönen, Ville Tirronen, and Michael Cochez. 2013. Issues with a course that emphasizes self-direction. In Proceedings of the 18th ACM Conference on Innovation and Technology in Computer Science Education (ITiCSE'13). Association for Computing Machinery, New York, NY, 111-116. DOI : https://doi.org/10.1145/2462476.2462495

[81] Viggo Kann and Anna-Karin Högfeldt. 2016. Effects of a program integrating course for students of computer science and engineering. In Proceedings of the 47th ACM Technical Symposium on Computer Science Education (SIGCSE'16). Association for Computing Machinery, New York, NY, 510-515. DOI : https://doi.org/10.1145/2839509.2844610

[82] Avi Kaplan. 2008. Clarifying metacognition, self-regulation, and self-regulated learning: What's the purpose? Educ. Psychol. Rev. 20, 4 (Sept. 2008), 477. DOI : https://doi.org/10.1007/s10648-008-9087-2

[83] Staffs Keele. 2007. Guidelines for Performing Systematic Literature Reviews in Software Engineering. Technical report 2.3. EBSE.

[84] Päivi Kinnunen and Lauri Malmi. 2008. CS minors in a CS1 course. In Proceedings of the 4th International Workshop on Computing Education Research (ICER'08). Association for Computing Machinery, New York, NY, 79-90. DOI : https: //doi.org/10.1145/1404520.1404529

[85] Päivi Kinnunen, Robert McCartney, Laurie Murphy, and Lynda Thomas. 2007. Through the eyes of instructors: A phenomenographic investigation of student success. In Proceedings of the 3rd International Workshop on Computing Education Research (ICER'07). ACM, New York, NY, 61-72. DOI : https://doi.org/10.1145/1288580.1288589

[86] Barbara Kitchenham, O. Pearl Brereton, David Budgen, Mark Turner, John Bailey, and Stephen Linkman. 2009. Systematic literature reviews in software engineering-A systematic literature review. Inf. Softw. Technol. 51, 1 (Jan. 2009), 7-15. DOI : https://doi.org/10.1016/j.infsof.2008.09.009

[87] Alice Kolb and David Kolb. 2005. The Kolb learning style inventory-version 3.12005 technical specifications. (Jan. 2005). Hay Resource Direct 200, 72 (2005), 166-171.

[88] David Kolb. 1984. Experiential Learning: Experience as the Source of Learning and Development. Vol. 1. FT Press.

[89] Vitomir Kovanović, Dragan Gašević, Shane Dawson, Srećko Joksimović, Ryan S. Baker, and Marek Hatala. 2015. Penetrating the black box of time-on-task estimation. In Proceedings of the 5th International Conference on Learning Analytics and Knowledge (LAK'15). ACM Press, 184-193. DOI : https://doi.org/10.1145/2723576.2723623 
[90] Vitomir Kovanović, Srećko Joksimović, Oleksandra Poquet, Thieme Hennis, Pieter de Vries, Marek Hatala, Shane Dawson, George Siemens, and Dragan Gašević. 2019. Examining communities of inquiry in massive open online courses: The role of study strategies. Internet High. Educ. 40 (Jan. 2019), 20-43. DOI : https://doi.org/10.1016/j.iheduc. 2018.09.001

[91] M. Kuehn, J. Estad, J. Straub, T. Stokke, and S. Kerlin. 2017. An expert system for the prediction of student performance in an initial computer science course. In Proceedings of the IEEE International Conference on Electro Information Technology (EIT'17). 1-6. DOI : https://doi.org/10.1109/EIT.2017.8053321

[92] Agnieszka Kurczewska, Paula Kyrö, Krista Lagus, Oskar Kohonen, and Tiina Lindh-Knuutila. 2018. The interplay between cognitive, conative, and affective constructs along the entrepreneurial learning process. Educ. + Train. 60, 7/8 (Jan. 2018), 891-908. DOI : https://doi.org/10.1108/ET-09-2016-0148

[93] Lisa L. Lacher and Mark C. Lewis. 2015. The effectiveness of video quizzes in a flipped class. In Proceedings of the 46th ACM Technical Symposium on Computer Science Education (SIGCSE'15). Association for Computing Machinery, New York, NY, 224-228. DOI : https://doi.org/10.1145/2676723.2677302

[94] Leo Leppänen, Juho Leinonen, and Arto Hellas. 2016. Pauses and spacing in learning to program. In Proceedings of the 16th Koli Calling International Conference on Computing Education Research (Koli Calling'16). Association for Computing Machinery, New York, NY, 41-50. DOI : https://doi.org/10.1145/2999541.2999549

[95] Soohyun Nam Liao, Sander Valstar, Kevin Thai, Christine Alvarado, Daniel Zingaro, William G. Griswold, and Leo Porter. 2019. Behaviors of higher and lower performing students in CS1. In Proceedings of the ACM Conference on Innovation and Technology in Computer Science Education (ITiCSE'19). Association for Computing Machinery, New York, NY, 196-202. DOI: https://doi.org/10.1145/3304221.3319740

[96] Fang-Ling Lin and Chyi-In Wu. 2018. Exploring the network dynamics in a flipped classroom. In Proceedings of the IEEE/ACM International Conference on Advances in Social Networks Analysis and Mining (ASONAM'18). IEEE Press, 855-860.

[97] Alf Lizzio, Keithia Wilson, and Roland Simons. 2002. University students' perceptions of the learning environment and academic outcomes: Implications for theory and practice. Stud. High. Educ. 27, 1 (Feb. 2002), 27-52. DOI : https: //doi.org/10.1080/03075070120099359

[98] M. Lorås and T. Aalberg. 2020. First year computing study behavior: Effects of educational design. In Proceedings of the IEEE Frontiers in Education Conference (FIE'20). 1-9. DOI : https://doi.org/10.1109/FIE44824.2020.9274285

[99] Jie Lu, K. L. Chin, Juan Yao, Jun Xu, and Jitian Xiao. 2010. Cross-cultural education: Learning methodology and behaviour analysis for Asian students in IT field of Australian universities. In Proceedings of the 12th Australasian Conference on Computing Education (ACE'10). Australian Computer Society, Inc., AUS, 117-126.

[100] Andrew Luxton-Reilly, Simon, Ibrahim Albluwi, Brett A. Becker, Michail Giannakos, Amruth N. Kumar, Linda Ott, James Paterson, Michael James Scott, Judy Sheard, and Claudia Szabo. 2018. Introductory programming: A systematic literature review. In Proceedings of the 23rd Annual ACM Conference on Innovation and Technology in Computer Science Education (ITiCSE'18). ACM, New York, NY, 55-106. DOI : https://doi.org/10.1145/3293881.3295779

[101] Jian Ma. 1994. Problem-based learning with database systems. Comput. Educ. 22, 3 (Apr. 1994), 257-263. DOI : https: //doi.org/10.1016/0360-1315(94)90007-8

[102] Lauri Malmi, Judy Sheard, and Päivi Kinnunen. 2019. Computing education theories: What are they and how are they used? In Proceedings of the 2019 ACM Conference on International Computing Education Research.

[103] Eric D. Manley and Timothy M. Urness. 2014. Video-based instruction for introductory computer programming. F. Comput. Sci. Coll. 29, 5 (May 2014), 221-227.

[104] Delia Marshall and Jennifer Case. 2005. “Approaches to learning” research in higher education: A response to Haggis Brit. Educ. Res. F. 31, 2 (2005), 257-267. DOI : https://doi.org/10.1080/014119205200340242

[105] Joshua Martin, Stephen H. Edwards, and Clfford A. Shaffer. 2015. The effects of procrastination interventions on programming project success. In Proceedings of the 11th Annual International Conference on International Computing Education Research (ICER'15). ACM, New York, NY, 3-11. DOI : https://doi.org/10.1145/2787622.2787730

[106] F. Marton and R. Säljö. 1976. On qualitative differences in learning: "outcome and process." Brit. F. Educ. Psychol. 46, 1 (Feb. 1976), 4-11. DOI : https://doi.org/10.1111/j.2044-8279.1976.tb02980.x

[107] Chris Masui, Jan Broeckmans, Sarah Doumen, Anne Groenen, and Geert Molenberghs. 2014. Do diligent students perform better? Complex relations between student and course characteristics, study time, and academic performance in higher education. Stud. High. Educ. 39, 4 (Apr. 2014), 621-643. DOI : https://doi.org/10.1080/03075079.2012.721350

[108] Patrícia Gomes Fernandes Matsubara and Caroline Lima Corrundefineda da Silva. 2017. Game elements in a software engineering study group: A case study. In Proceedings of the 39th International Conference on Software Engineering: Software Engineering and Education Track (ICSE-SEET'17). IEEE Press, 160-169. DOI : https://doi.org/10.1109/ICSESEET.2017.8

[109] Robert McCartney, Anna Eckerdal, Jan Erik Mostrom, Kate Sanders, and Carol Zander. 2007. Successful students' strategies for getting unstuck. In Proceedings of the 12th Annual SIGCSE Conference on Innovation and Technology in Computer Science Education (ITiCSE'07). ACM, New York, NY, 156-160. DOI : https://doi.org/10.1145/1268784.1268831 
[110] J. H. F. Meyer and M. W. Muller. 1990. Evaluating the quality of student learning. An unfolding analysis of the association between perceptions of learning context and approaches to studying at an individual level. Stud. High. Educ. 15, 2 (Jan. 1990), 131-154. DOI : https://doi.org/10.1080/03075079012331377471

[111] Craig S. Miller and Amber Settle. 2011. When practice doesn't make perfect: Effects of task goals on learning computing concepts. ACM Trans. Comput. Educ. 11, 4 (Nov. 2011). DOI : https://doi.org/10.1145/2048931.2048933

[112] A. Moffat, B. Hughes, H. Søndergaard, and P. Gruba. 2005. Making connections: First year transition for computer science and software engineering students, Vol. 42. 229-238.

[113] P. Mota, F. S. Melo, and L. Coheur. 2015. Modeling students self-studies behaviors, Vol. 3. 1521-1528.

[114] Matti Nelimarkka and Arto Hellas. 2018. Social help-seeking strategies in a programming MOOC. In Proceedings of the 49th ACM Technical Symposium on Computer Science Education (SIGCSE'18). Association for Computing Machinery, New York, NY, 116-121. DOI : https://doi.org/10.1145/3159450.3159495

[115] Philip M. Newton. 2015. The learning styles myth is thriving in higher education. Front. Psychol. 6 (2015). DOI : https //doi.org/10.3389/fpsyg.2015.01908

[116] Philip M. Newton and Atharva Salvi. 2020. How common is belief in the learning styles neuromyth, and does it matter? A pragmatic systematic review. Front. Educ. 5 (2020). DOI : https://doi.org/10.3389/feduc.2020.602451

[117] G. S. Ng and E. Y. K. Ng. 1997. Undergraduate students in a computer engineering course: A perspective of their learning approaches and motivation factors. Innov. Educ. Train. Int. 34, 1 (Feb. 1997), 65-69. DOI : https://doi.org/\{10. $1080 / 1355800970340110\}$

[118] M. Nkhoma, N. Sriratanaviriyakul, H. P. Cong, and T. K. Lam. 2014. Examining the mediating role of learning engagement, learning process and learning experience on the learning outcomes through localized real case studies. Educ. Train. 56, 4 (2014), 287-302. DOI : https://doi.org/10.1108/ET-01-2013-0005

[119] Sarath A. Nonis and Gail I. Hudson. 2006. Academic performance of college students: Influence of time spent studying and working. 7. Educ. Bus. 81, 3 (Jan. 2006), 151-159. DOI : https://doi.org/10.3200/JOEB.81.3.151-159

[120] Ezekiel Okike. 2014. Investigating' achievements in computing science using human metric. Int. F. Advanc. Comput. Sci. Applic. 5, 4 (2014). DOI : https://doi.org/10.14569/IJACSA.2014.050426

[121] C. Ott, A. Robins, P. Haden, and K. Shephard. 2015. Illustrating performance indicators and course characteristics to support students' self-regulated learning in CS1. Comput. Sci. Educ. 25, 2 (2015), 174-198. DOI : https://doi.org/10. 1080/08993408.2015.1033129

[122] H. Oysaed, R. Andersen, P. E. Garmannslund, A. Prinz, A. Lazareva, and M. Schmidt. 2017. Does the introduction of an overall study strategy empower students to use appropriate study strategies? In Proceedings of the 10th International Conference of Education, Research, and Innovation (ICERI'17). 4152-4157.

[123] Harold Pashler, Mark McDaniel, Doug Rohrer, and Robert Bjork. 2008. Learning styles: Concepts and evidence. Psychol. Sci. Pub. Int. 9, 3 (Dec. 2008), 105-119. DOI : https://doi.org/10.1111/j.1539-6053.2009.01038.x

[124] Arnold Pears, Philip East, Robert McCartney, Mark Bartley Ratcliffe, Ioanna Stamouli, Anders Berglund, Päivi Kinnunen, Jan-Erik Moström, Carsten Schulte, Anna Eckerdal et al. 2007. What's the problem? Teachers' experience of student learning successes and failures. In Proceedings of the 7th Baltic Sea Conference on Computing Education Research (Koli Calling'07). Australian Computer Society, Inc., AUS, 207-211.

[125] Andrew Petersen, Michelle Craig, Jennifer Campbell, and Anya Tafliovich. 2016. Revisiting why students drop CS1. In Proceedings of the 16th Koli Calling International Conference on Computing Education Research (Koli Calling'16). ACM, New York, NY, 71-80. DOI : https://doi.org/10.1145/2999541.2999552

[126] Kerstin Pettersson, Maria Svedin, Max Scheja, and Olle Bälter. 2018. Approaches to studying in first-year engineering Comparison between inventory scores and students' descriptions of their approaches through interviews. High. Educ. 75, 5 (May 2018), 827-838. DOI : https://doi.org/10.1007/s10734-017-0172-7

[127] Maria da Graça C. Pimentel, Cristiane A. Yaguinuma, Diogo S. Martins, and Isabela Zaine. 2019. Anchoring interactive points of interest on web-based instructional video: Effects on students' interaction behavior and perceived experience. In Proceedings of the 34th ACM/SIGAPP Symposium on Applied Computing (SAC'19). Association for Computing Machinery, New York, NY, 2445-2452. DOI : https://doi.org/10.1145/3297280.3297521

[128] E. Ashby Plant, K. Anders Ericsson, Len Hill, and Kia Asberg. 2005. Why study time does not predict grade point average across college students: Implications of deliberate practice for academic performance. Contemp. Educ. Psychol. 30, 1 (Jan. 2005), 96-116. DOI : https://doi.org/10.1016/j.cedpsych.2004.06.001

[129] Arthur E. Poropat. 2009. A meta-analysis of the five-factor model of personality and academic performance. Psychol. Bull. 135, 2 (Mar. 2009), 322-338. DOI : https://doi.org/10.1037/a0014996

[130] James Prather, Brett A. Becker, Michelle Craig, Paul Denny, Dastyni Loksa, and Lauren Margulieux. 2020. What do we think we think we are doing? Metacognition and self-regulation in programming. In Proceedings of the ACM Conference on International Computing Education Research (ICER'20). Association for Computing Machinery, New York, NY, 2-13. DOI : https://doi.org/10.1145/3372782.3406263

[131] James Prather, Raymond Pettit, Kayla McMurry, Alani Peters, John Homer, and Maxine Cohen. 2018. Metacognitive difficulties faced by novice programmers in automated assessment tools. In Proceedings of the ACM Conference 
on International Computing Education Research (ICER'18). ACM, New York, NY, 41-50. DOI : https://doi.org/10.1145/ 3230977.3230981

[132] Justus J. Randolph, George Julnes, Erkki Sutinen, and Steve Lehman. 2008. A methodological review of computer science education research. J. Inf. Technol. Educ.: Res. 7, 1 (Jan. 2008), 135-162.

[133] John T. E. Richardson. 2015. Approaches to learning or levels of processing: What did Marton and Säljö really say? The legacy of the work of the Göteborg Group in the 1970s. Interchange 46, 3 (Aug. 2015), 239-269. DOI: https: //doi.org/10.1007/s10780-015-9251-9

[134] Anthony Robins, Janet Rountree, and Nathan Rountree. 2003. Learning and teaching programming: A review and discussion. Comput. Sci. Educ. 13, 2 (June 2003), 137-172. DOI : https://doi.org/10.1076/csed.13.2.137.14200

[135] Anna Sandström and Mats Daniels. 2000. Time studies as a tool for (computer science) education research. In Proceedings of the Australasian Conference on Computing Education (ACSE'00). ACM, New York, NY, 208-214. DOI : https: //doi.org/10.1145/359369.359401

[136] M. Scheidt, R. Senkpeil, J. Chen, A. Godwin, and E. Berger. 2019. SAT does not spell success: How non-cognitive factors can explain variance in the GPA of undergraduate engineering and computer science students, Vol. 2018October. In IEEE Frontiers in Education Conference (FIE). DOI : https://doi.org/10.1109/FIE.2018.8658989

[137] Howard Schuman, Edward Walsh, Camille Olson, and Barbara Etheridge. 1985. Effort and reward: The assumption that college grades are affected by quantity of study. Soc. Forces 63, 4 (1985), 945-966. DOI : https://doi.org/10.2307/ 2578600

[138] Amber Settle, John Lalor, and Theresa Steinbach. 2015. Evaluating a linked-courses learning community for development majors. In Proceedings of the 16th Annual Conference on Information Technology Education (SIGITE'15). Association for Computing Machinery, New York, NY, 127-132. DOI : https://doi.org/10.1145/2808006.2808031

[139] Steven C. Shaffer. 2005. Ludwig: An online programming tutoring and assessment system. SIGCSE Bull. 37, 2 (June 2005), 56-60. DOI : https://doi.org/10.1145/1083431.1083464

[140] J. Sheard, A. Carbone, D. Chinn, and M. Laakso. 2013. Study habits of CS 1 students: What do they say they do? In Proceedings of the Learning and Teaching in Computing and Engineering Conference. 122-129. DOI : https://doi.org/10. 1109/LaTiCE.2013.46

[141] Varshita Sher, Marek Hatala, and Dragan Gaševiundefined. 2019. On multi-device use: Using technological modality profiles to explain differences in students' learning. In Proceedings of the 9th International Conference on Learning Analytics \& Knowledge (LAK'19). Association for Computing Machinery, New York, NY, 1-10. DOI : https://doi.org/ 10.1145/3303772.3303790

[142] Adithya Sheshadri, Niki Gitinabard, Collin F. Lynch, Tiffany Barnes, and Sarah Heckman. 2018. Predicting student performance based on online study habits: A study of blended courses. In Proceedings of the 11th International Conference on Educational Data Mining (EDM'18).

[143] Nikki Sigurdson and Andrew Petersen. 2018. An exploration of grit in a CS1 context. In Proceedings of the 18th Koli Calling International Conference on Computing Education Research (Koli Calling'18). Association for Computing Machinery, New York, NY. DOI : https://doi.org/10.1145/3279720.3279743

[144] Simon, Sally Fincher, Anthony Robins, Bob Baker, Ilona Box, Quintin Cutts, Michael de Raadt, Patricia Haden, John Hamer, Margaret Hamilton, Raymond Lister, Marian Petre, Ken Sutton, Denise Tolhurst, and Jodi Tutty. 2006. Predictors of success in a first programming course. In Proceedings of the 8th Australasian Conference on Computing Education (ACE'06). Australian Computer Society, Inc., 189-196.

[145] J. F. Superby, J. P. Vandamme, and N. Meskens. 2006. Determination of factors influencing the achievement of the first-year university students using data mining methods. In Proceedings of the Workshop on Educational Data Mining.

[146] F. Sustelo and P. Guerreiro. 2010. Analyzing self-reflection by computer science student to identify bad study habits: Self-reflection performed by students of programming courses on the study habits and skills acquired through blearning supported by an automatic judge. In IEEE Educon 2010. 263-270. DOI : https://doi.org/10.1109/EDUCON.2010. 5492568

[147] M. Svedin and O. Bälter. 2016. Gender neutrality improved completion rate for all. Comput. Sci. Educ. 26, 2-3 (2016), 192-207. DOI : https://doi.org/10.1080/08993408.2016.1231469

[148] Claudia Szabo, Nickolas Falkner, Andrew Petersen, Heather Bort, Kathryn Cunningham, Peter Donaldson, Arto Hellas, James Robinson, and Judy Sheard. 2019. Review and use of learning theories within computer science education research: Primer for researchers and practitioners. In Proceedings of the Working Group Reports on Innovation and Technology in Computer Science Education (ITiCSE-WGR'19). Association for Computing Machinery, New York, NY, 89-109. DOI : https://doi.org/10.1145/3344429.3372504

[149] Neena Thota. 2011. Repertory grid: Investigating personal constructs of novice programmers. In Proceedings of the 11th Koli Calling International Conference on Computing Education Research (Koli calling'11). Association for Computing Machinery, New York, NY, 23-32. DOI : https://doi.org/10.1145/2094131.2094137

[150] Vincent Tinto. 1988. Stages of student departure: Reflections on the longitudinal character of student leaving. F. High Educ. 59, 4 (1988), 438-455. DOI : https://doi.org/10.2307/1981920 
[151] Denise Tolhurst. 2004. The influence of web-supported independent activities and small group work on students' epistemological beliefs. In Proceedings of the 6th Australasian Conference on Computing Education (ACE'04). Australian Computer Society, Inc., AUS, 311-316.

[152] Tara Tressel, Susanne P. Lajoie, and Melissa C. Duffy. 2019. A guide for study terminology: Reviewing a fragmented domain. Canad. Psychol./Psychologie canadienne 60, 2 (2019), 115. DOI : https://doi.org/10.1037/cap0000138

[153] Marcel V. J. Veenman, Laura Bavelaar, Levina De Wolf, and Marieke G. P. Van Haaren. 2014. The on-line assessment of metacognitive skills in a computerized learning environment. Learn. Indiv. Dif. 29 (Jan. 2014), 123-130. DOI : https: //doi.org/10.1016/j.lindif.2013.01.003

[154] Arto Vihavainen, Juha Helminen, and Petri Ihantola. 2014. How novices tackle their first lines of code in an IDE: Analysis of programming session traces. In Proceedings of the 14th Koli Calling International Conference on Computing Education Research (Koli Calling'14). Association for Computing Machinery, New York, NY, 109-116. DOI : https://doi. org/10.1145/2674683.2674692

[155] Klinge Orlando Villalba-Condori, Sonia Esther Castro Cuba-Sayco, Evelyn Paola Guillen Chávez, Claudia Deco, and Cristina Bender. 2018. Approaches of learning and computational thinking in students that get into the computer sciences career. In Proceedings of the 6th International Conference on Technological Ecosystems for Enhancing Multiculturality (TEEM'18). Association for Computing Machinery, New York, NY, 36-40. DOI : https://doi.org/10.1145/ 3284179.3284185

[156] Robert Vinaja. 2014. The use of lecture videos, EBooks, and clickers in computer courses. f. Comput. Sci. Coll. 30, 2 (Dec. 2014), 23-32.

[157] H. Wan, K. Liu, Q. Yu, and X. Gao. 2019. Pedagogical intervention practices: Improving learning engagement based on early prediction. IEEE Trans. Learn. Technol. 12, 2 (2019), 278-289. DOI : https://doi.org/10.1109/TLT.2019.2911284

[158] Rui Wang, Gabriella Harari, Peilin Hao, Xia Zhou, and Andrew T. Campbell. 2015. SmartGPA: How smartphones can assess and predict academic performance of college students. In Proceedings of the ACM International foint Conference on Pervasive and Ubiquitous Computing (UbiComp'15). Association for Computing Machinery, New York, NY, 295306. DOI : https://doi.org/10.1145/2750858.2804251

[159] F. Weng, F. Cheong, and C. Cheong. 2010. The combined effect of self-efficacy and academic integration on higher education students studying IT majors in Taiwan. Educ. Inf. Technol. 15, 4 (2010), 333-353. DOI: https://doi.org/10. 1007/s10639-009-9115-y

[160] L. K. Westin and M. Nordstrom. 2004. Teaching OO concepts-A new approach. In Proceedings of the 34th Annual Frontiers in Education Conference. F3C-6. DOI : https://doi.org/10.1109/FIE.2004.1408620

[161] Keith J. Whittington, Dianne P. Bills, and Lawrence W. Hill. 2003. Implementation of alternative pacing in an introductory programming sequence. In Proceedings of the 4th Conference on Information Technology Curriculum (CITC4'03). Association for Computing Machinery, New York, NY, 47-53. DOI : https://doi.org/10.1145/947121.947132

[162] Gita C. Williams, Richard Bialac, and Yi Liu. 2006. Using online self-assessment in introductory programming classes. f. Comput. Sci. Coll. 22, 2 (Dec. 2006), 115-122.

[163] Laurie Williams, Eric Wiebe, Kai Yang, Miriam Ferzli, and Carol Miller. 2002. In support of pair programming in the introductory computer science course. Comput. Sci. Educ. 12, 3 (Sept. 2002), 197-212. DOI: https://doi.org/10.1076/ csed.12.3.197.8618

[164] Salla Willman, Rolf Lindén, Erkki Kaila, Teemu Rajala, Mikko-Jussi Laakso, and Tapio Salakoski. 2015. On study habits on an introductory course on programming. Comput. Sci. Educ. 25, 3 (July 2015), 276-291. DOI : https://doi.org/ 10.1080/08993408.2015.1073829

[165] Christopher A. Wolters, Sungjun Won, and Maryam Hussain. 2017. Examining the relations of time management and procrastination within a model of self-regulated learning. Metacog. Learn. 12, 3 (Dec. 2017), 381-399. DOI : https: //doi.org/10.1007/s11409-017-9174-1

[166] Iman YeckehZaare, Paul Resnick, and Barbara Ericson. 2019. A spaced, interleaved retrieval practice tool that is motivating and effective. In Proceedings of the ACM Conference on International Computing Education Research (ICER'19). Association for Computing Machinery, New York, NY, 71-79. DOI : https://doi.org/10.1145/3291279.3339411

[167] Sang Yim, Christopher Lowrance, and Eric Sturzinger. 2019. Effects of YouTube video as pre-lecture preparation. In Proceedings of the ASEE Annual Conference \& Exposition. ASEE Conferences. DOI : https://doi.org/10.18260/1-2--32697

[168] Halil Yurdugul and Nihal Menzi Cetin. 2015. Investigation of the relationship between learning process and learning outcomes in e-learning environments. Euras. f. Educ. Res. 59 (2015), 57-74. DOI : https://doi.org/\{10.14689/ejer.2015. $59.4\}$

[169] D. Zehetmeier, A. Böttcher, A. Brüggemann-Klein, V. Thurner, and K. Schlierkamp. 2015. Finding competence characteristics among first semester students in computer science. In Proceedings of the IEEE Frontiers in Education Conference (FIE'15). 1-9. DOI : https://doi.org/10.1109/FIE.2015.7344201

[170] Y. Zhang, T. Zhang, Y. Jia, J. Sun, F. Xu, and W. Xu. 2017. DataLab: Introducing software engineering thinking into data science education at scale. In Proceedings of the IEEE/ACM 39th International Conference on Software Engineering: 
Software Engineering Education and Training Track (ICSE-SEET'17). 47-56. DOI : https://doi.org/10.1109/ICSE-SEET. 2017.7

[171] H. Zhao, Y. Guo, K. Wang, M. Lu, and X. Yan. 2019. The Effects of ICT Use on Chinese college' study behavior in b-learning evaluating b-learning effectiveness via causal model. In Proceedings of the 14th International Conference on Computer Science Education (ICCSE'19). 103-107. DOI : https://doi.org/10.1109/ICCSE.2019.8845333

[172] Daniel Zingaro, Michelle Craig, Leo Porter, Brett A. Becker, Yingjun Cao, Phill Conrad, Diana Cukierman, Arto Hellas, Dastyni Loksa, and Neena Thota. 2018. Achievement goals in CS1: Replication and extension. In Proceedings of the 49th ACM Technical Symposium on Computer Science Education (SIGCSE'18). Association for Computing Machinery, New York, NY, 687-692. DOI : https://doi.org/10.1145/3159450.3159452

[173] Daniel Zingaro and Leo Porter. 2016. Impact of student achievement goals on CS1 outcomes. In Proceedings of the 47th ACM Technical Symposium on Computer Science Education (SIGCSE'16). Association for Computing Machinery, New York, NY, 279-296. DOI : https://doi.org/10.1145/2839509.2844553

[174] Gökhan Özsoy, Aysel Memiş, and Turan Temur. 2009. Metacognition, study habits and attitudes. Int. Electron. J Element. Educ. 2, 1 (2009), 154-166.

Received October 2020; revised June 2021; accepted July 2021 